\title{
Analysis of Spatiotemporal Evolution of Isolated Rainstorm Events in Huai River Basin, China
}

\author{
Simin Liu, ${ }^{1,2}$ Hao Wang, ${ }^{1,2,3}$ Denghua Yan, ${ }^{2,3}$ Qingfu Ren, ${ }^{1,2}$ Duo Wang, ${ }^{4}$ and Boya Gong ${ }^{2,3}$ \\ ${ }^{1}$ School of Soil and Water Conservation, Beijing Forestry University, No. 35 Tsinghua East Road, Haidian District, \\ Beijing 100083, China \\ ${ }^{2}$ State Key Laboratory of Simulation and Regulation of Water Cycle in River Basin, China Institute of Water Resources and \\ Hydropower Research, 1-A Fuxing Road, Haidian District, Beijing 100038, China \\ ${ }^{3}$ Department of Water Resources, China Institute of Water Resources and Hydropower Research, A-922, 1 Yuyuantan South Road, \\ Haidian District, Beijing 100038, China \\ ${ }^{4}$ Beijing Huayu Engineering Co., Ltd., No. 67 Ande Road, Xicheng District, Beijing 100120, China
}

Correspondence should be addressed to Hao Wang; wanghao@iwhr.com

Received 21 October 2016; Accepted 22 December 2016; Published 1 March 2017

Academic Editor: Hossein Tabari

Copyright (c) 2017 Simin Liu et al. This is an open access article distributed under the Creative Commons Attribution License, which permits unrestricted use, distribution, and reproduction in any medium, provided the original work is properly cited.

Because of the impacts of extreme climate, the severity, areal extent, and frequency of rainstorm events are rapidly increasing, especially in the Huai River Basin of China. This article is based on hourly precipitation data of 229 meteorological stations from 1951 through 2012, combined with statistical and meteorological theory. We used the Mann-Kendall mutation test, moving $t$-test, and inverse distance weighting spatial interpolation to analyze the spatiotemporal evolution of precipitation, duration, intensity, and frequency of isolated rainstorm events under climate change. The main results are as follows: (1) isolated rainstorm events were obviously bimodal and their occurrence moved backward in time. Their average duration and time of maximum intensities changed dramatically, without a significant increasing trend. The period since the 2000s has seen an increase of rainstorms and their temporal regression across the entire basin. (2) The intensity of isolated rainstorm events in the study area decreased, but precipitation, its duration, areal extent, and frequency had increasing trends basin-wide. (3) Four rainstorm event indices were examined for the period of 1990-2000. Relative to the years before 2003, the average precipitation increased by $2.1 \%$, the average total duration by $8.1 \%$, and the average frequency of occurrence by $25.5 \%$. All indices show smaller minimum and larger maximum values. Overall, the isolated rainstorm events tended to increase.

\section{Introduction}

Climate change and variability have already affected global ecosystems and biodiversity and the socioeconomy [1]. In recent decades, there have been many significant changes caused by extreme climatic events, which can lead to devastating effects on human society and the environment $[2,3]$. These impacts are likely to be more pronounced in the future [4]. Heavy precipitation events have been increasing since $1950[5,6]$. With rising temperatures, the trend of extreme precipitation events may accelerate [7]. Such precipitation events can trigger local river flooding disasters, which will damage a lot of farmland, environmental facilities, and so forth [8]. Based on measurements at meteorological stations in the Huai Basin, Du et al. showed that annual maximum precipitation has had a rising trend [9]. Fu et al. demonstrated an increasing trend of extreme precipitation events in the Yangtze River Basin [10]. Liu et al. analyzed change of extreme temperature and precipitation in China, and the results indicate a rising trend in precipitation days [11]. They also showed that variability in extreme precipitation produces uneven spatiotemporal distribution [12]. Climate change in China is unequivocal [13-16]. The average atmospheric temperature is $1.23^{\circ} \mathrm{C}$ higher than that in the 1950 s, based on measurements at 156 meteorological stations [17]. Average temperature increased by approximately $0.035,0.03,0.018$, and $0.02^{\circ} \mathrm{C} /$ year respectively, in northwestern, northeastern, southwestern, and southeastern parts of the country over the 


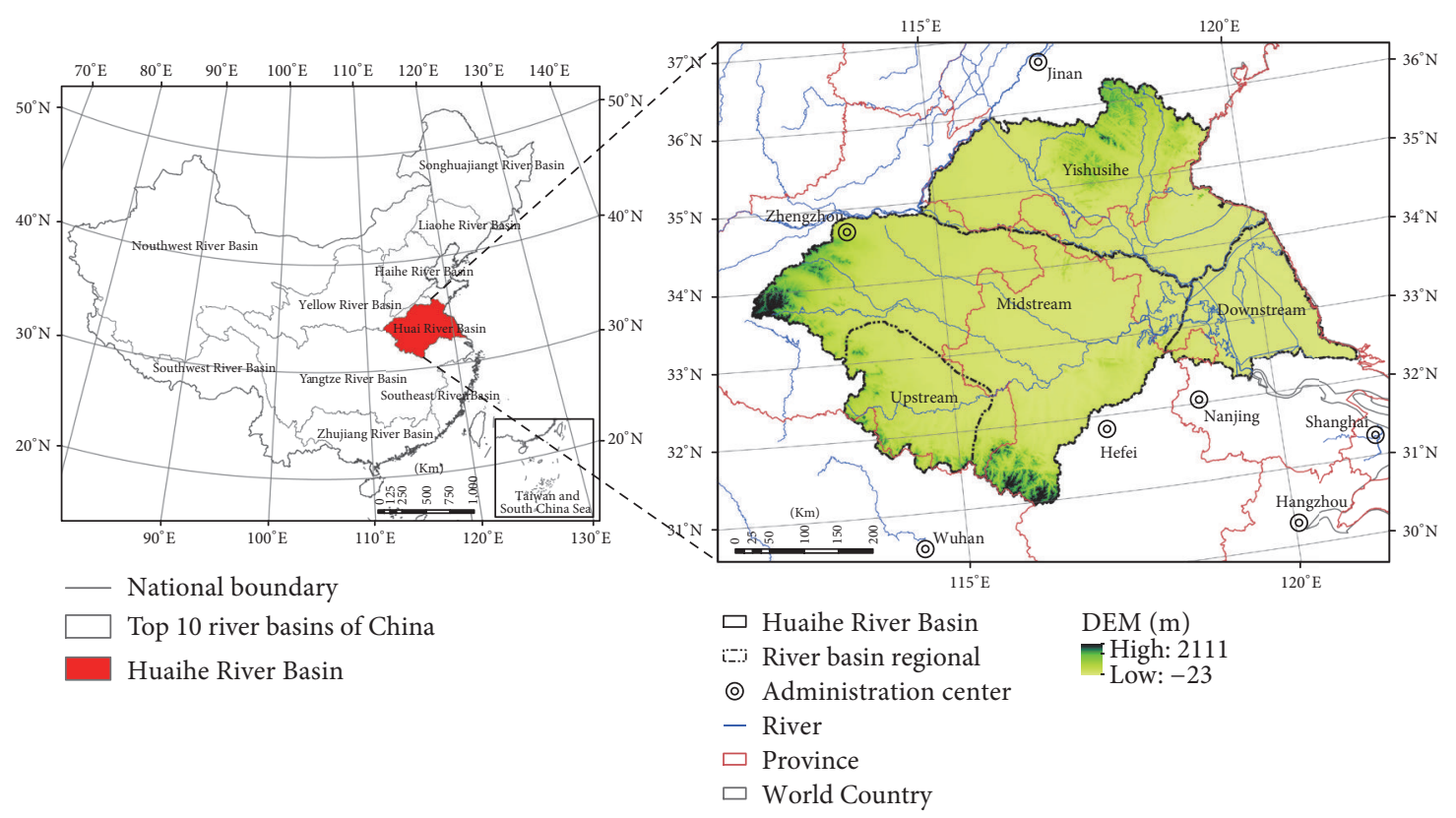

Figure 1: Location of Huai River Basin in China.

past 60 years [18-21]. In recent years, affected by El Niño, rainstorm disaster frequency and duration in China have increased $[22,23]$. Thus, in the storm and flood season, there is an urban waterlogging phenomenon in the country that will become more serious. This has negative effects on the regional ecological environment and socioeconomy.

Currently, research into rainstorm events has been largely based on atmospheric circulation or water vapor transport, in order to analyze a specific event. Most studies have used a single indicator for the event, which can elucidate the cause of a single case in detail [24-27]. However, there has rarely been a study of patterns emerging from a large number of cases. Furthermore, research into rainstorm processes often takes provincial and municipal administrative regions as main objects and treats the relationship between city waterlogging and those processes [28-33], but investigations of entire basins for isolated rainstorm events are few. Such an event lasts for short periods, typically a few hours. High temporal-resolution (e.g., hours) heavy rainstorm data can be used to accurately describe basic characteristics of physical processes in an isolated event; however, given limitations of data accuracy in space and time, prior research into rainstorms was largely of daily precipitation change, and few studies have used high-resolution data to study the change of rainstorm processes [34, 35].

In this paper, the Huai River Basin is the study area, where rainstorms are frequent and intense. Using high-resolution hourly precipitation data collected over the last 62 years and combining statistical methods with the actual situation of the basin, we analyzed the impact of the extreme climate on the rainstorm process for the period of 1951-2012. We examined spatiotemporal variability of rainstorm events in the basin under the background of extreme climate and the response of rainstorm indicators to that change, thereby providing a scientific basis for the distribution and building of hydraulic engineering facilities in the basin and the construction of a "sponge city" at basin scale.

\section{Study Areas and Data Sources}

2.1. Study Area. The Huai River Basin (area $2.7 \times 10^{5} \mathrm{~km}^{2}$ ) is in Eastern China, between the Yellow and Yangtze, the two longest rivers in the country. With the geographic coordinates $111^{\circ} 56^{\prime}-111^{\circ} 42^{\prime} \mathrm{E}$ and $30^{\circ} 57^{\prime}-37^{\circ} 50^{\prime} \mathrm{N}$, the basin can be divided into 4 zones corresponding to upstream, midstream, downstream, and Yishusi (Figure 1). The western, southwestern, and northeastern parts of the basin contain the Funiu, Dabie, and Yimeng Mountains, respectively, constituting $3.3 \%$ of the total basin area [36]. Mountainous and plain areas are $9.1 \times 10^{4}$ and $1.8 \times 10^{5} \mathrm{~km}^{2}$, respectively, and the annual average precipitation is $880 \mathrm{~mm}$ [37]. The spatial and temporal distributions of precipitation are very asymmetric, and the interannual variation of precipitation is very large so waterlogging disaster has also become more serious since 1950 [38]. Flood disaster caused by heavy rain has become one of the "bottleneck" factors that restrict the development of ecology, economy, and society in the Huai Basin, and this situation will persist for years. In this paper, we mainly address spatiotemporal changes of isolated rainstorm events in the basin.

2.2. Observed Data. We used hourly precipitation data (from 1951 through 2012) from 229 meteorological stations in the Huai River Basin. Stations near the basin boundary were also considered (Figure 2). The data for the study period were chosen for their continuous availability without interruption. The number of rainstorms and total number of stations in various years are shown in Figure 3. Climate data were obtained 


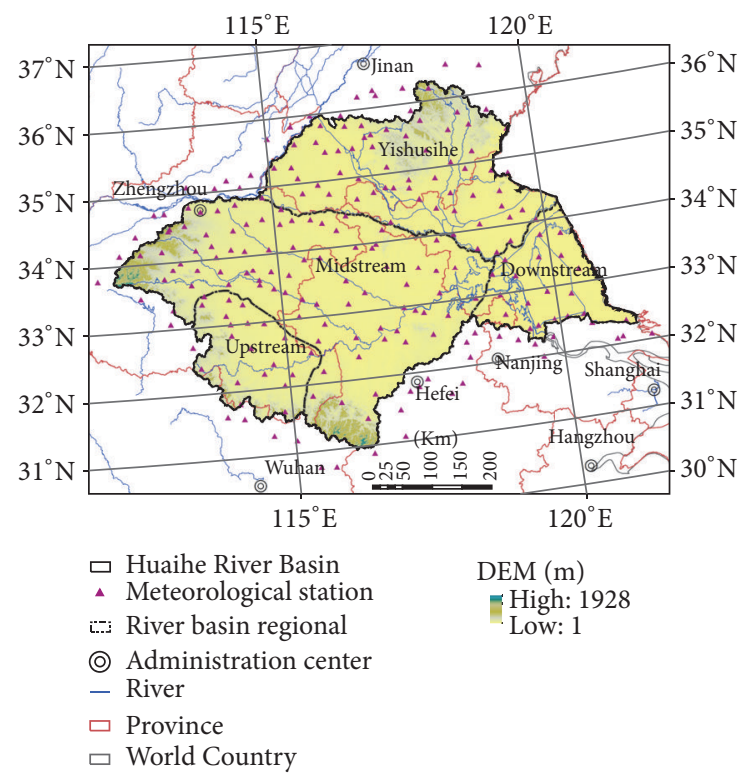

FIGURE 2: The 229 national meteorological stations in the Huai River Basin.

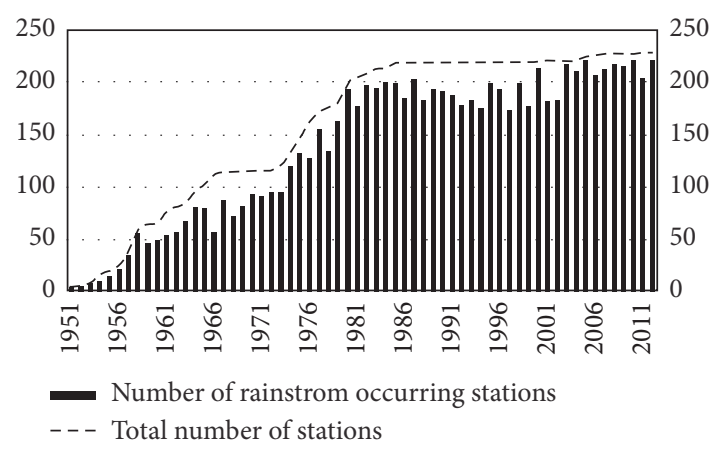

FIGURE 3: Rainstorm occurrence stations in different years.

from the China Meteorological Data Sharing Service System (http://data.cma.cn/). Basic terrain data were acquired from the National Basic Geographic Information System of the Huai River Basin (1:250000). Social and economic data originated from the Statistical Yearbook of China, whereas related data of the water conservancy project in the basin were taken from the latest Water Conservancy Survey.

\section{Methodology}

3.1. Definition and Screening of Isolated Rainstorm Events. The classification of rainfall events was based on the shortest time between rainfall events [39]. Cumulative rainfall $\geqslant 50 \mathrm{~mm} / 24 \mathrm{~h}$ has been used as the definition of isolated rainstorm events [40,41]. That is, in prior research, $24 \mathrm{~h}$ was taken as the division for the next rainfall events, based on daily precipitation data. However, per our research aims, we could not artificially separate an isolated precipitation event into different parts according to $24 \mathrm{~h}$ days. This is because storms are too frequent in the Huai River Basin.
TABLE 1: Definition of indices of rainstorm events.

\begin{tabular}{|c|c|c|}
\hline Name of index & Definition & Units \\
\hline Precipitation (Ra) & $\begin{array}{l}\text { Total rainfall amount during } \\
\text { entire isolated rainstorm event }\end{array}$ & $\mathrm{mm}$ \\
\hline Duration $(T)$ & $\begin{array}{l}\text { Total duration of entire isolated } \\
\text { rainstorm event (beginning to } \\
\text { end) }\end{array}$ & $\mathrm{h}$ \\
\hline Intensity (In) & $\mathrm{In}=\mathrm{Ra} / T$ & $\mathrm{~mm} / \mathrm{h}$ \\
\hline Frequency (St) & $\begin{array}{l}\text { Frequency of occurrence of } \\
\text { storm events over time }\end{array}$ & Number \\
\hline $\begin{array}{l}\text { Occurrence time } \\
\left(T_{0}\right)\end{array}$ & Start time of a storm event & d \\
\hline $\begin{array}{l}\text { Time to attainment } \\
\text { of maximum }\left(T_{m}\right)\end{array}$ & $\begin{array}{l}\text { Elapsed time from start to } \\
\text { maximum intensity }\end{array}$ & $\mathrm{h}$ \\
\hline
\end{tabular}

Thus, we defined an intervening period of $5 \mathrm{~h}$ to separate 2 storm events. Based on the above rationale, we screened out cumulative rainfall durations $\leqslant 24 \mathrm{~h}$ and events with precipitation amount $\geqslant 50 \mathrm{~mm}$, which identified one part of isolated rainstorm events. For storm events lasting more than $24 \mathrm{~h}$ and total rainfall in excess of $50 \mathrm{~mm}$, we filtered the events by an index of intensity $(\geqslant 2.0 \mathrm{~mm} / \mathrm{h})$ to obtain another part of isolated rainstorm events. The original data were sorted and analyzed using FORTRAN and MATLAB programming languages, as well as the ArcGIS 10.2 and Origin 9.0 platforms.

3.2. Rainstorm Event Indices. We grouped the data of 62 years (1951-2012) into the following 6 periods: 1950s (19511959), 1960s (1960-1969), 1970s (1970-1979), 1980s (19801989), 1990s (1990-1999), and 2000s (2000-2012). To eliminate errors caused by data of series length across different periods, we used the averages of the indices for every isolated rainstorm event in the time periods. There were 6 indicators chosen to characterize the process of isolated rainstorm events (Table 1).

3.3. Spatial Interpolation of Hourly Rainstorm Events. Currently, there are 3 types of principal interpolation methods: inverse distance weighting (IDW), kriging, and spline curve [42-44].

Because the meteorological stations are sufficiently dense to capture the Huai Basin surface variations [45], we chose IDW to convert isolated storm events as observed by the 229 meteorological stations to a grid surface. Spatial resolution of the interpolated hourly rainstorm events was $500 \times 500 \mathrm{~m}^{2}$. The data processing was done on the ArcInfo Workstation 10.2 platform. The ArcGIS Python language was also used for estimation.

3.4. Mann-Kendall Rank Correlation Test. The Mann-Kendall (MK) test is a nonparametric statistical test method [46-48]. It calculates the standardization of time series statistics to determine the change trend of sequence $M . M>0$ means increasing (rising) and $M<0$ means decreasing (falling). 

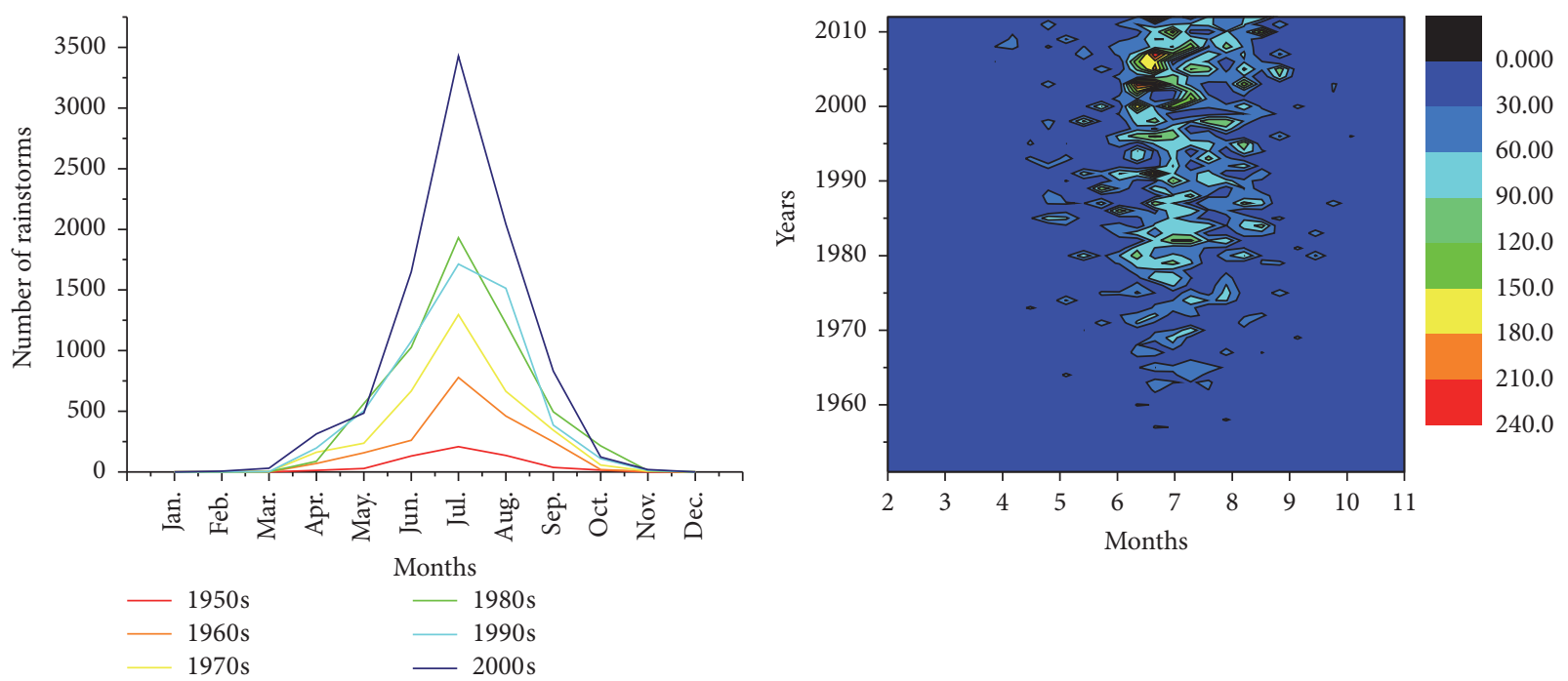

FIgURE 4: Monthly variation of rainstorm process by period.

$|M|>1.282$ indicates that the time series reached $90 \%$ significance, and $|M|>1.645$ indicates the attainment of $95 \%$ significance $[49,50]$.

3.5. Abrupt Change Test of Isolated Rainstorm Events. Mutation of the climate sequence is an important and widespread phenomenon. This indicates a climate jump from one stable state to another. There are many ways to study climatic mutations that increase the reliability of testing for such mutations. Based on qualitative understanding of the spatial distribution and evolution of rainstorm events, we selected the MK mutation test and sliding $t$-test.

MK Test. MK is a common method for studying mutations. The samples do not need to follow a certain distribution and are unaffected by interference from a few outliers [51]. Under the independent assumption of random time sequence, we established

$$
\mathrm{UF}_{k}=\frac{\left[S_{k}-E\left(S_{k}\right)\right]}{\sqrt{\operatorname{Var}\left(S_{k}\right)}}, \quad(k=1,2,3, \ldots, n),
$$

where $\mathrm{UF}_{k}$ is for the standard normal distribution according to the time sequence $x_{1}, x_{2}, \ldots, x_{n}$, as calculated by the following sequence of statistics. We used UF and UB, which represent the curve of statistical sequence and reverse curve for various indicators of rainstorm events, and these were given a level of significance (e.g., $\alpha=0.05$ ), that is, U0.05 $= \pm 1.96$. A UF or UB value greater than zero indicates a rising trend, and a value less than zero a downward trend.

Moving $t$-Test. The moving $t$-test is a statistical method of mutation that tests the differences of 2 groups of sample means. The key to the test is to study the mutation to determine if there is a significant difference between the 2 groups.
Specific methods refer to Yang et al. (2013), Tao et al. (2011), and Yang et al. (2011) [52-54]. The equation for the moving $t$-test is

$$
t=\frac{\overline{x_{1}}-\overline{x_{2}}}{s \sqrt{1 / n_{1}}+\sqrt{1 / n_{2}}} .
$$

In the data sequence of 62 years there may be multiple mutations. The 2 methods above have advantages and disadvantages. Thus, it is appropriate to combine the MK test and moving $t$-test to determine the mutation year.

\section{Results and Discussion}

4.1. Temporal Variation of Rainstorm Processes. After statistical processing of isolated rainstorm data from the Huai Basin, we found that rainstorm events were mainly between May and September (with the monthly average more than twice the annual average). Each event duration was generally 1-3 days, which accounted for 94.3\% (24,536 instances) of the annual total. The frequency of isolated rainstorm events between the 1950s and 2000s is shown in Figure 4, which reveals a clear coexisting trend of "longer and extreme." To study changes of isolated rainstorm processes, we selected the representative period between May and September using intervals of every 10 days. We used "ftd," "mtd," and "ltd" to represent the first 10 , middle 10 , and last 10 days of a month, respectively.

(1) Start Time of Isolated Rainstorm Events. There were differences in statistical data series and number of meteorological stations between years. Thus, we used the ratio of the frequency of isolated rainstorm events in each 10-day interval divided by the total number of isolated rainstorm events in that interval as the contribution rate $(R)$, to analyze variations in the start time of isolated rainstorm events (Table 2).

The event start time showed a bimodal character during the year and obvious differences between the 10-day intervals 
TABLE 2: Contribution rate of rainstorm events and their start times based on 10-day intervals, in $\%$.

\begin{tabular}{|c|c|c|c|c|c|c|}
\hline 10-day intervals & $R_{1950 \mathrm{~s}}$ & $R_{1960 \mathrm{~s}}$ & $R_{1970 \mathrm{~s}}$ & $R_{1980 \mathrm{~s}}$ & $R_{1990 \mathrm{~s}}$ & $R_{2000 \mathrm{~s}}$ \\
\hline May_ftd & 3.31 & 3.04 & 1.81 & 3.45 & 2.83 & 2.52 \\
\hline May_mtd & 0.92 & 3.51 & 3.71 & 4.16 & 3.19 & 1.26 \\
\hline May_ltd & 1.10 & 1.78 & 1.90 & 3.13 & 3.68 & 1.96 \\
\hline Jun_ftd & 9.19 & 1.83 & 4.21 & 5.50 & 2.42 & 2.49 \\
\hline Jun_mtd & 2.02 & 1.73 & 4.86 & 6.70 & 6.68 & 3.40 \\
\hline Jun_ltd & 12.87 & 10.12 & 11.68 & 7.40 & 11.64 & 13.68 \\
\hline Jul_ftd & 16.18 & 16.04 & 13.55 & 10.78 & 12.45 & 17.39 \\
\hline Jul_mtd & 13.79 & 13.73 & 13.58 & 13.36 & 13.78 & 11.99 \\
\hline Jul ltd & 8.46 & 11.11 & 13.27 & 12.71 & 6.74 & 11.25 \\
\hline Aug_ftd & 7.17 & 9.07 & 6.01 & 7.08 & 11.99 & 7.72 \\
\hline Aug_mtd & 9.38 & 9.01 & 9.63 & 6.56 & 8.83 & 6.52 \\
\hline Aug_ltd & 8.64 & 6.03 & 5.05 & 9.71 & 8.31 & 9.98 \\
\hline Sep_ftd & 4.78 & 6.81 & 5.36 & 6.64 & 3.98 & 4.29 \\
\hline Sep_mtd & 0.55 & 3.14 & 3.89 & 1.70 & 2.52 & 4.34 \\
\hline Sep_ltd & 1.65 & 3.04 & 1.50 & 1.11 & 0.94 & 1.23 \\
\hline
\end{tabular}

(Figure 5). Most events were between the last 10 days of April and the middle 10 days of September. The most concentrated precipitation in the $1950 \mathrm{~s}-2000$ s was $R_{1950 \mathrm{~s}}\left(\mathrm{Jul} \_\mathrm{ftd}\right)=16.18 \%$, $R_{1960 \mathrm{~s}}\left(\right.$ Jul_ftd) $=16.04 \%, R_{1970 \mathrm{~s}}\left(\right.$ Jul_mtd) $=13.58 \%, R_{1980 \mathrm{~s}}$ $($ Jul_mtd $)=13.36 \%, R_{1990 s}\left(\right.$ Jul_mtd) $=17.39 \%$, and $R_{2000 s}$ (Jul_ftd) $=17.39 \%$. This finding accounted for the highest percentage in the first and middle 10 days of July. Therefore, the highest contribution rate of event occurrence time in the 1950 s to 1960 s was in the first 10 days of July, gradually decreasing to the first maximum value of intensity. Then, in the last 10 days of July and the first 10 days of August, there was again a rising trend, toward the second peak period. In that period, the onset of isolated rainstorm events moved backward in time. In the 1970s-1990s compared with the $1950 \mathrm{~s}-1960 \mathrm{~s}$, the highest $R$ shifted to the middle 10 days of July. During the 2000s, the highest $R$ returned to the first 10 days of that month. When we compared it with the period earlier than the historical period, there were 2 obvious peak periods overall. The major peak concentrated in mid-July, and the secondary peak in the last 10 days of August.

(2) Duration of Isolated Rainstorm Events and Their Peak Intensities. Figure 6 shows interannual variation of the average duration of isolated rainstorms and their time to attainment of peak intensities at 229 meteorological stations in the basin between 1961 and 2012. This includes annual variation of the duration of isolated rainstorms and time of their peak intensities (panels (a) and (b)) and of anomaly percentages of the duration and time of their peak intensities (panels (c) and (d)). These diagrams show the following: (1) the duration of an isolated rainstorm (panel (a)) and time of peak intensity (panel (b)) had increasing trends, between $0.2 \mathrm{~h} / 10 \mathrm{a}$ and $0.1 \mathrm{~h} / 10 \mathrm{a}$, respectively. The MK rank correlation test calculated the $M$-values of the duration peak intensities at 1.2270 and 0.9476 , respectively, neither of which was significant. (2) The longest duration of attaining peak rainstorm intensity was in 1969 , at $10.20 \mathrm{~h}$. There were other long durations in 1967, 2000, 1968, 2007, and 2003, around
$9.50 \mathrm{~h}$. The shortest duration of attaining peak rainstorm intensity was also in 1969, only $4.25 \mathrm{~h}$. (3) The average duration of an isolated rainstorm and time to attainment of its peak intensity, as well as the interannual percentage variation of their anomalies changed dramatically in the Huai Basin. The anomaly percentage is in the range $\pm 20 \%$, which means that the yearly duration is very similar to the average of many years. By analyzing the anomaly percentage of the average duration of an isolated rainstorm, we found 58 years (which accounted for $93.6 \%$ of the total number of years) for which the duration was similar to the long-term average. There were 4 years $(3.3 \%$ of all years) in which the anomaly percentage was less than $-20 \%$, and no year had $>20 \%$. By analyzing the anomaly percentage of the average time to attainment of peak rainstorm intensity, we found 49 years $(79.0 \%$ of the total years) for which the duration was similar to the long-term average. There were 11 years when the anomaly percentage was less than $-20 \%$ and 2 years when it was $>20 \%$, representing $17.7 \%$ and $6.4 \%$ of the total number of years, respectively.

\subsection{Spatial Distribution and Evolution Analysis}

(1) Spatial Precipitation Distribution of Isolated Rainstorm Events. As seen from the spatial precipitation distribution (Figure 7), large precipitation values of isolated rainstorm events were upwind of mountainous areas, that is, west of the Huai midstream (Figure 1) and the Yishusi River Basin. In the 1960s-1980s, the average annual precipitation of the events showed a decreasing trend, but isolated rainstorm precipitation in the southern mountainous areas was relatively heavy. In the 1950s, an area of maximum precipitation appeared in the Northern Yishusi Basin in contrast with other periods. The reason for this difference was that this basin had rainstorm floods in 1957. The spatial pattern of isolated rainstorm events has been affected by the monsoon circulation since the 1990s, leading to increased precipitation in the south and 

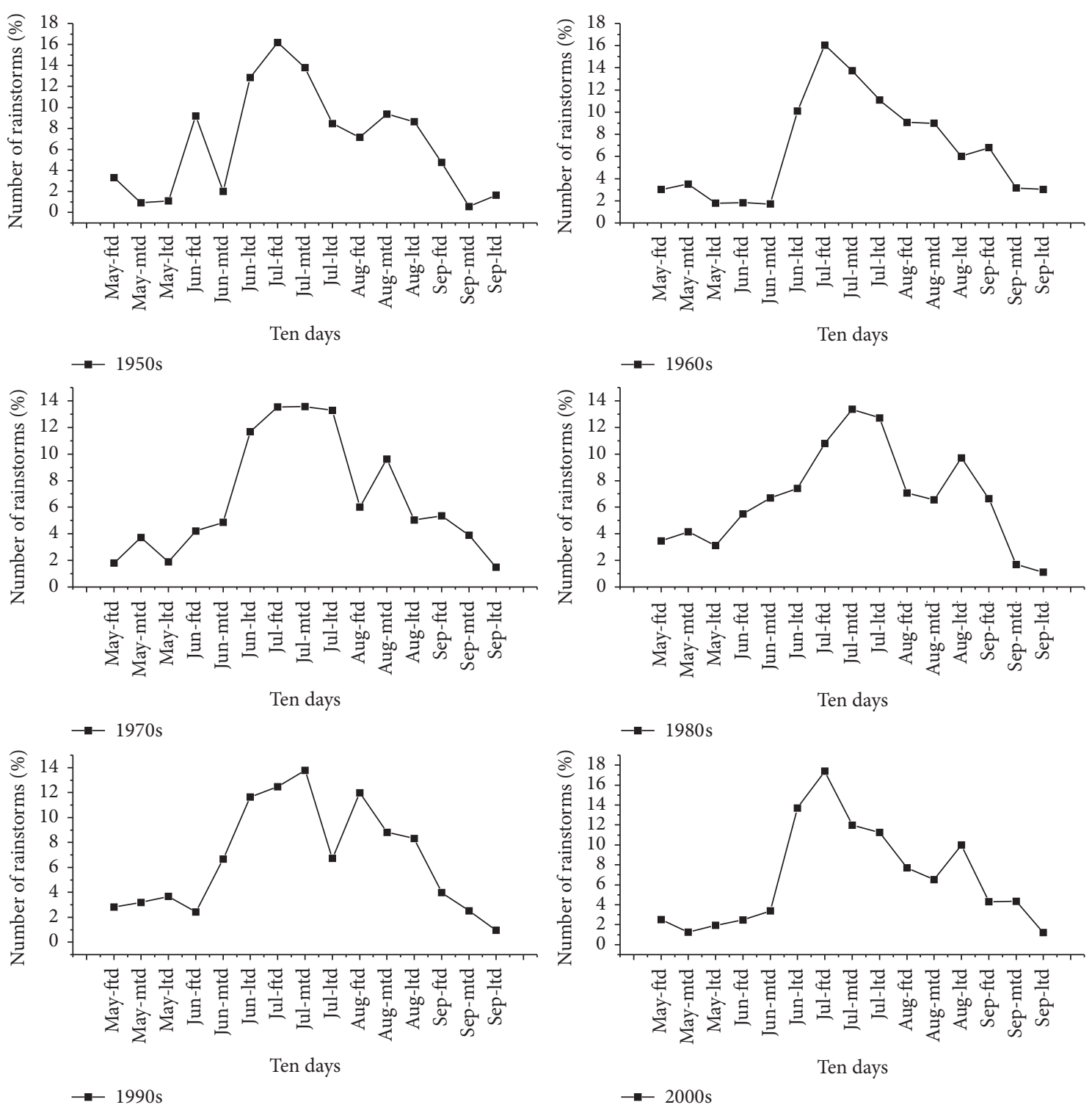

FIGURE 5: Variation of rainstorm events in ten-day intervals during 1950s-2000s.

decreased precipitation in the north. Some isolated areas of heavy precipitation values are related to terrain, especially piedmont windward areas. In the 2000s, the spatial extent of the isolated rainstorm average precipitation substantially increased. Overall, the isolated precipitation increased in the Southern Huai Basin and decreased in its north. Hence, the probability of "southern flood and northern drought" in the basin will increase.

(2) Spatial Distribution of Isolated Rainstorm Event Duration. Spatial distribution of the durations of isolated rainstorm events is shown in Figure 8. This depicts long durations toward the southwest and short ones toward the northeast. With respect to interannual variability, the distribution of spatial duration shows an increasing trend from the northwestern to southeastern areas. During the 1950s-1970s, there was an average event duration of $\sim 22 \mathrm{~h}$ in the downstream area. The coverage area of this duration increased between the 1970s and the 2000s. The coverage area of long duration rainstorms began to move from the southwestern to northeastern area and even to the entire basin. The main reason for this phenomenon is likely to be the anomalous atmospheric monsoon circulation in recent years, combined with the special topography (mountain ranges) effects of the basin. This coverage in the area upstream of mountains gradually decreased and moved to the southern and the northwestern portions of midstream Huai. Most basin areas were covered by events of durations $<19 \mathrm{~h}$ in the past, but currently, most basin areas were covered by events of $>19 \mathrm{~h}$ duration. The coverage of the 19-22-h duration rapidly increased.

In recent years, many weather systems affect the Huaihe River Basin, such as the northwesterly trough, cold vortex; tropical typhoon, easterly wave; Jianghuai shear line, cyclonic wave. Atmospheric circulation anomaly is probably the main 


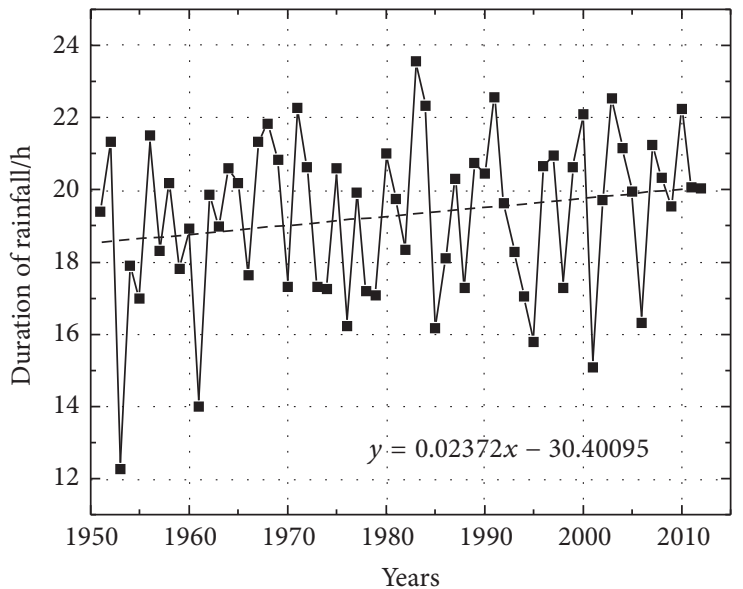

(a)

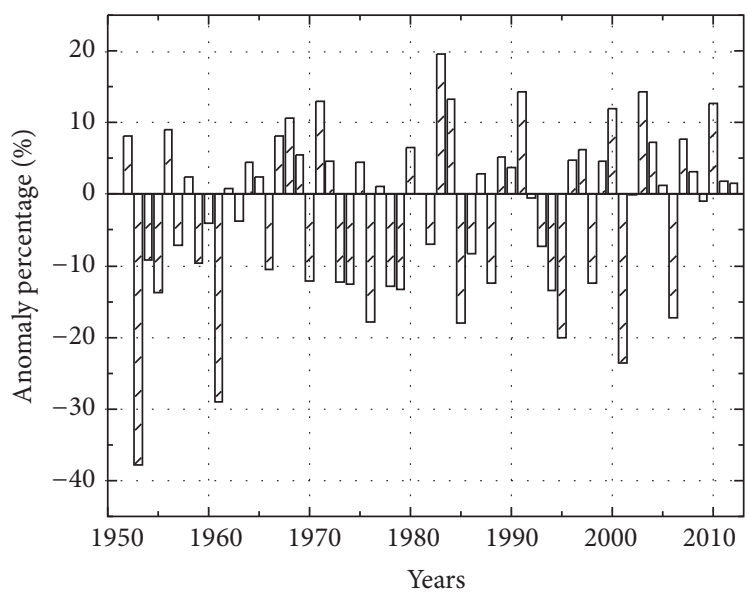

(c)

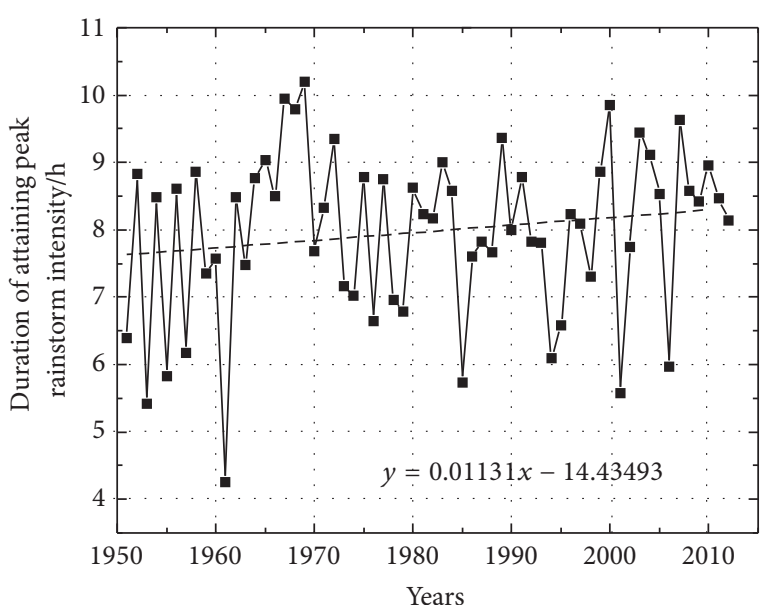

(b)

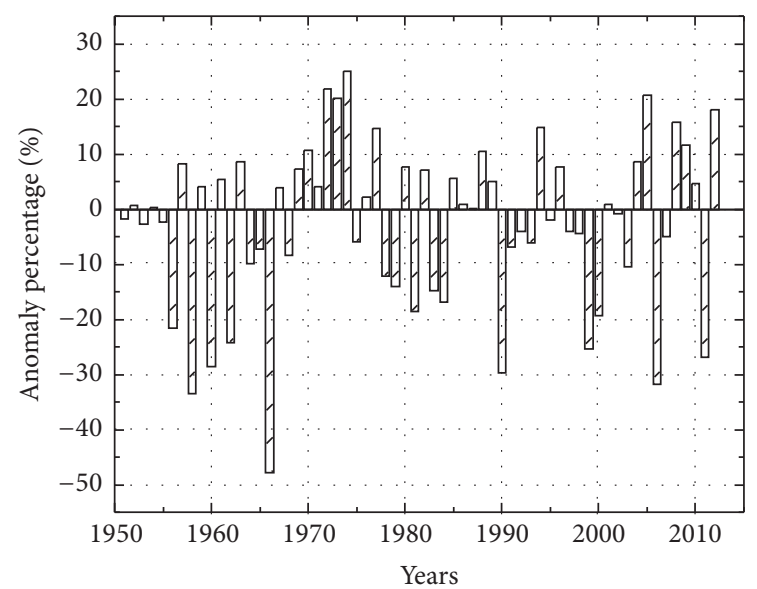

(d)

FIGURE 6: Variation of average duration of isolated rainstorms and their peak intensities.

factor causing the anomaly of precipitation events. It will cause the study area to be affected by various weather systems, and these relationships might be effective targets for future physically based work.

(3) Spatial Distribution of Frequency of Isolated Rainstorm Events. Per statistics from the period of 1950-2012, 26,017 isolated rainstorm events occurred across the Huai Basin. The spatial distributions of average occurrence frequency of these events across different periods were basically the same (Figure 9). They all showed a gradually increasing trend from northwest to southeast. Areas of high frequency interannual variability showed a gradually increasing trend in the southwest, and the extent of these areas increased. The increasing trend of the events and frequency of occurrence over the entire basin were significantly affected by extreme climate beginning in the 1990s.

(4) Spatial Distribution of Intensity of Isolated Rainstorm Events. The spatial distribution of isolated rainstorm event intensity was very similar to that during the 1960s-2000s. The intensity substantially decreased from northwest to southeast in the basin (Figure 10). The dominant event intensity in the 1960 s was $\sim 5-6 \mathrm{~mm} / \mathrm{h}$, which gradually declined to $\sim 4$ $5 \mathrm{~mm} / \mathrm{h}$ in the $2000 \mathrm{~s}$.

4.3. Mutation Analysis. As stated above, extreme climate has had a profound effect on the process of isolated rainstorm events in the Huai River Basin. Based on qualitative understanding of the spatial distribution and evolution of such events, we determined the mutation points of various indicators by combining the MK abrupt change and moving $t$-test methods. This combination provides scientific and reasonable means to confirm the indicator mutation points.

On inspection of Figure 11(a), we see that the intersection of the UF and UB curves occurred in 2003, after which there was an upward trend. However, there was no mutation in 2003 from the moving $t$-test; it showed a mutation in 1984. From the MK statistics curve (Figures 11(d), 11(f), and 11(h)), the UF and UB curves of average duration and rainstorm frequency intersect in 2003. The UF statistics of 3 types of MK curve have the same direction and increasing trend, but the moving $t$-test statistics curve (Figures 11(c), 11(e), and $11(\mathrm{~g})$ ) indicates no point at all. Analogously, for event intensity 

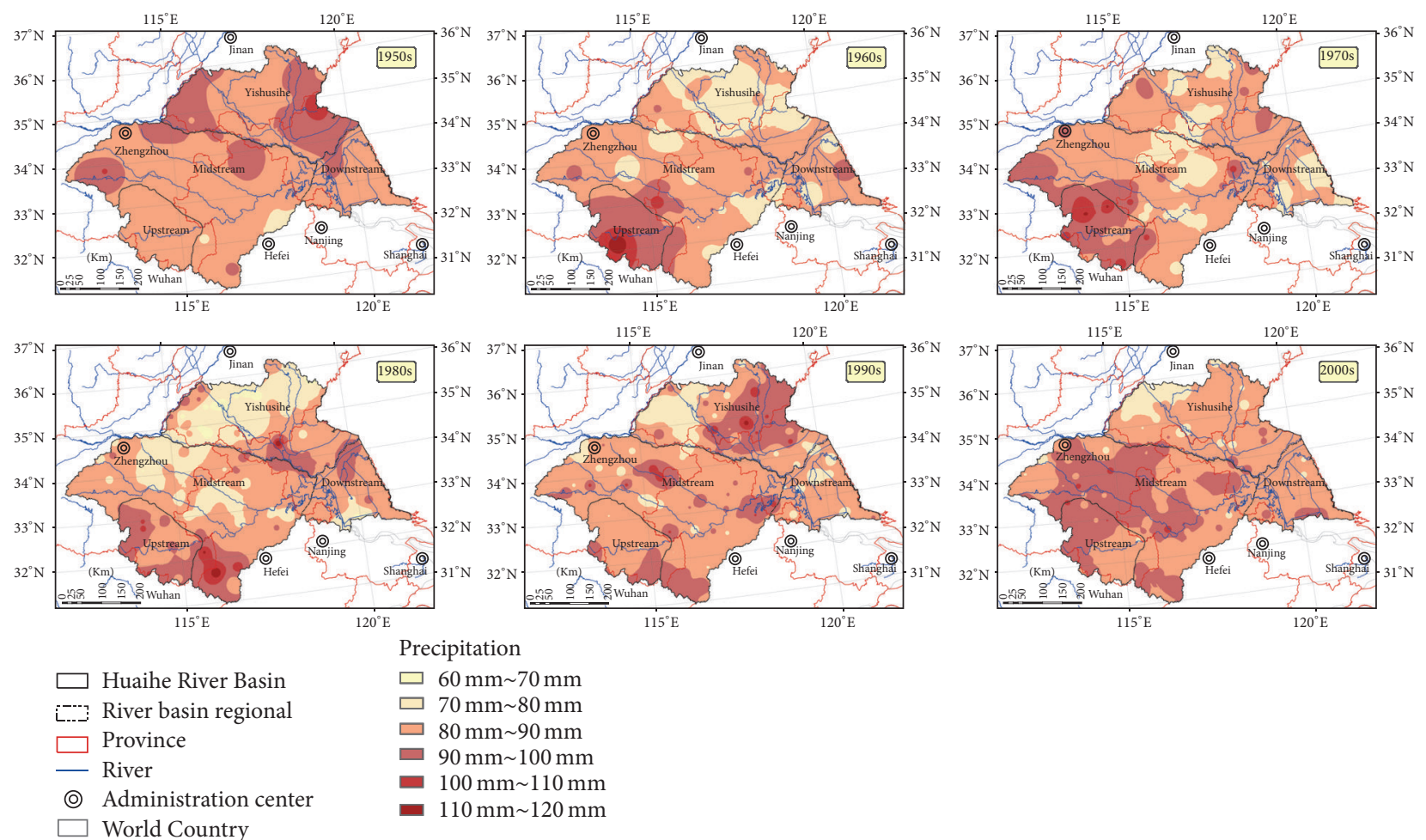

FIGURE 7: Spatial distribution of isolated rainstorm event precipitation during 1950s-2000s.
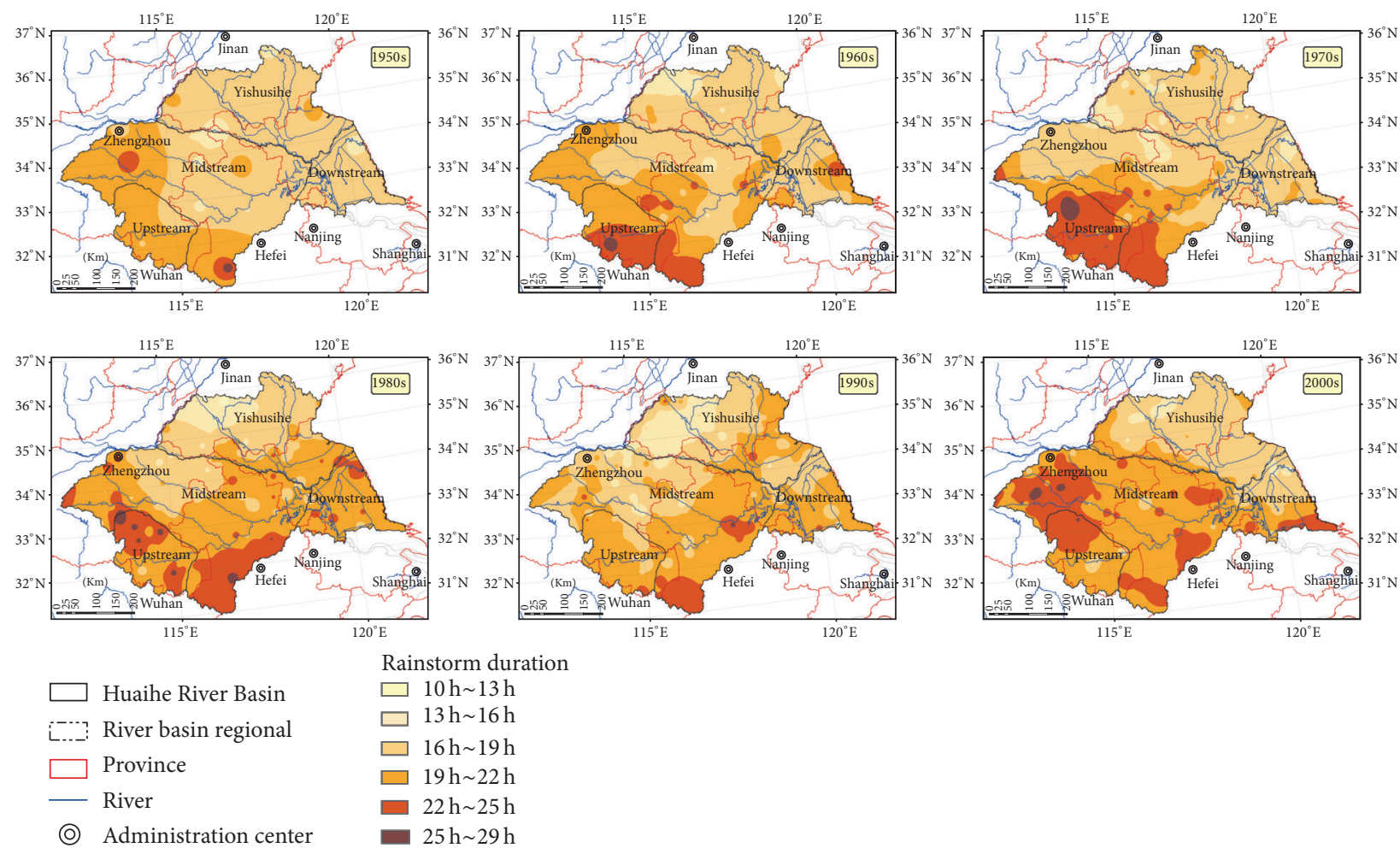

(0) Administration center $25 \mathrm{~h} \sim 29 \mathrm{~h}$

World Country

FIGURE 8: Spatial distribution of isolated rainstorm event duration during 1950s-2000s. 



Value

Frequen

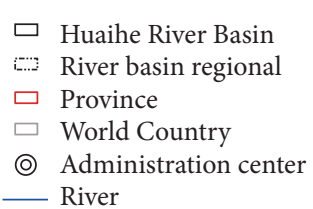

High: 5

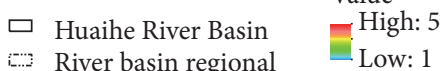

: River basin regional

$\square$ Province

$\square$ World Country

() Administration center

River

FIGURE 9: Spatial distribution of isolated rainstorm event frequency during 1950s-2000s.

changes, from the MK statistics curve, the UF and UB curves intersected around 1955-1958 (Figure 11(h)), but the moving $t$-test showed no mutations in this period, but there was 1 in 1990 (Figure 11(g)). This discrepancy is attributable to the shortcomings of the 2 methods. From both the statistical yearbook and flood control plans in the Huai Basin, we know that there were persistent rainstorms in July 2003. With the background of El Niño events during 2002-2003, extreme precipitation across all of southwestern China was mutated [55]. This means that the MK mutation test for precipitation, duration, and frequency was more accurate. Correlation data also indicates that, in 1991, there was widespread severe flooding in the Changjiang-Huai River Basin, with greater intensity and more extensive areas of impact rarely seen in a calendar year [56]. This shows that the moving $t$-test had a more accurate detection of the mutation of intensity. From the combined analysis above, we confirmed the mutation points of the various indicators. Then, using the MK rank correlation test, we obtained the specific results as follows in Table 3.

As shown in Table 3, before 1990, isolated rainstorm intensity ranged from 4.1 to $7.8 \mathrm{~mm} / \mathrm{h}$. However, in later years, the lowest intensity was $3.9 \mathrm{~mm} / \mathrm{h}$ and the maximum was
$10.6 \mathrm{~mm} / \mathrm{h}$, so the maximum value increased. Compared to the years prior to 1990, average event intensity decreased $9.36 \%$, minimum intensity declined $4.9 \%$, and the maximum increased $35.9 \%$. Except for a significant intensity decrease (Figure 13), the indicators of precipitation (Figure 12), frequency (Figure 15), and duration (Figure 14) of the events all showed an increasing trend. Relative to the years before 2003, average precipitation increased by $2.1 \%$, average duration by $8.1 \%$, and average frequency of occurrence by $25.5 \%$. Obviously, the current situation of isolated rainstorm events reveals a very high frequency and long duration. Moreover, all indicators show decreasing minimum values and increasing maxima, which threatens to greatly increase abrupt alternation between drought and flood disaster risk.

Based on the above analysis of the study area, it has been shown that, after the 1990s, the event of rainstorms in the whole area showed the influence range increased, as did the characteristics of long duration and high frequency. The combined influences of topography, monsoon circulation, and vapor transportation were the possible causes of the phenomenon. Previous studies reveal that the frequency of extreme climate events shows a close linkage with changes in extreme precipitation that are positively correlated 

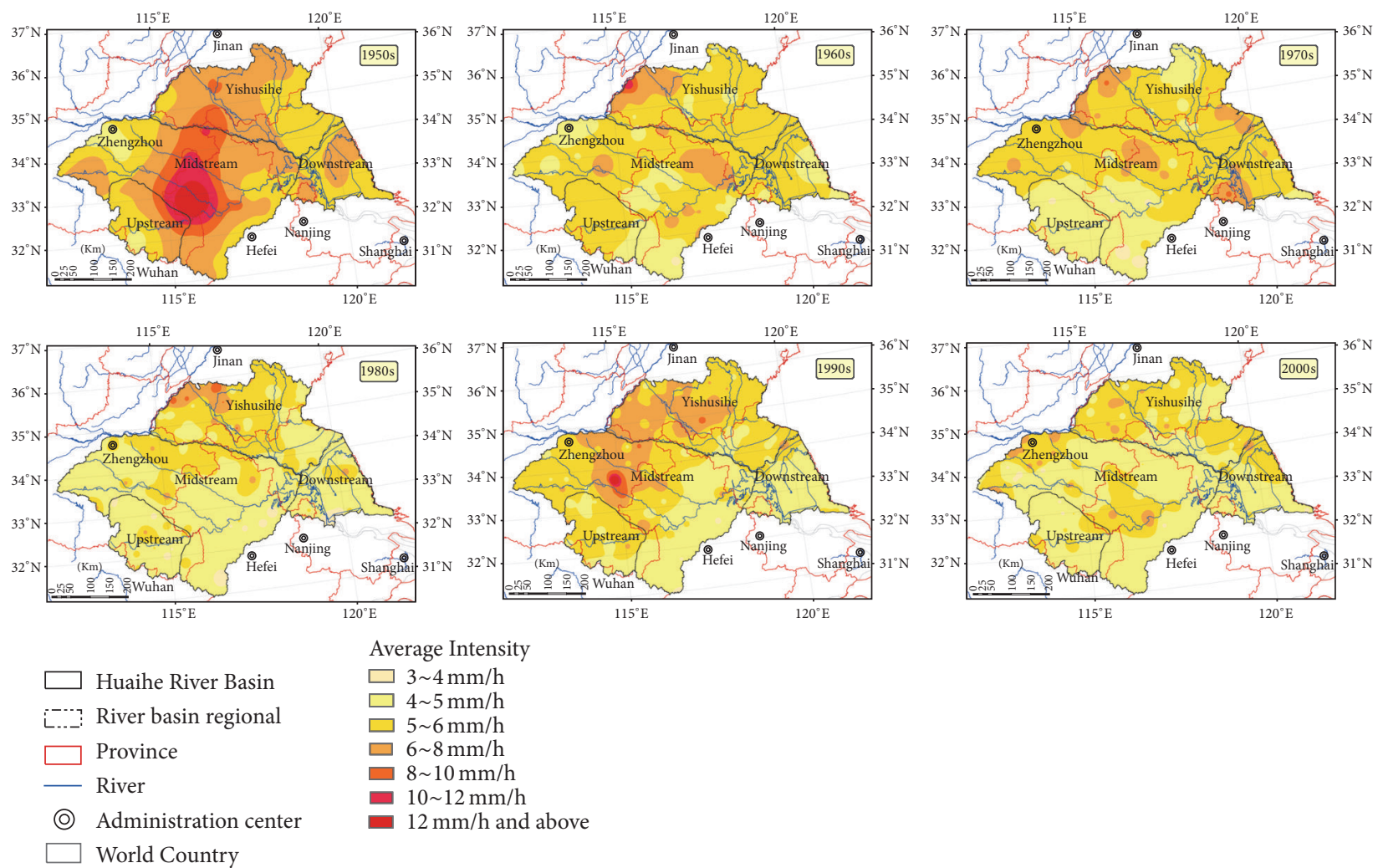

FIGURE 10: Spatial distribution of isolated rainstorm event intensity during 1950s-2000s.

TABLE 3: Mutation and trend analysis of each index.

\begin{tabular}{|c|c|c|c|c|c|c|}
\hline Mutation year & & $\begin{array}{c}\text { Before } \\
\text { mutation }\end{array}$ & $\begin{array}{c}\text { After } \\
\text { mutation }\end{array}$ & Standard statistics & $M$-value & Trend analysis \\
\hline \multirow{3}{*}{ Intensity (1990) } & Min & 4.08 & 3.89 & \multirow{3}{*}{$1.645(\alpha=0.05)$} & \multirow{3}{*}{$-1.652 \downarrow$} & \multirow{3}{*}{ Significant decrease } \\
\hline & Max & 7.82 & 10.58 & & & \\
\hline & Mean & 5.61 & 5.13 & & & \\
\hline \multirow{3}{*}{ Precipitation (2003) } & Min & 75.14 & 71.45 & \multirow{3}{*}{$1.645(\alpha=0.05)$} & \multirow{3}{*}{$0.705 \uparrow$} & \multirow{3}{*}{ No significant increase } \\
\hline & $\operatorname{Max}$ & 97.32 & 109.17 & & & \\
\hline & Mean & 85.68 & 87.34 & & & \\
\hline \multirow{3}{*}{ Duration (2003) } & Min & 14.81 & 14.86 & \multirow{3}{*}{$1.645(\alpha=0.05)$} & \multirow{3}{*}{$1.227 \uparrow$} & \multirow{3}{*}{ No significant increase } \\
\hline & $\operatorname{Max}$ & 24.73 & 28.65 & & & \\
\hline & Mean & 19.00 & 20.54 & & & \\
\hline \multirow{3}{*}{ Frequency (2003) } & Min & 2.02 & 1.26 & \multirow{3}{*}{$1.645(\alpha=0.05)$} & \multirow{3}{*}{$0.632 \uparrow$} & \multirow{3}{*}{ No significant increase } \\
\hline & $\operatorname{Max}$ & 4.15 & 5.20 & & & \\
\hline & Mean & 2.81 & 3.47 & & & \\
\hline
\end{tabular}

with the total precipitation [57-60]. Macroscopic analysis of climate variability was taken into consideration under the background of large-scale atmospheric circulation [6165]. Former studies set in Eastern China concluded that regional climate extremes could probably be modulated by several circulation patterns or oscillation indices, including the Western North Pacific Monsoon Index (WNPMI), the Arctic Oscillation Index (AOI), and the East Asian Summer Monsoon Index (EASMI) [66]. Additionally, other factors, such as total annual precipitation, northward movement and enhancement of the subtropical anticyclone, and anthropogenic ally induced greenhouse forcing, can also contribute to the changes in extreme climate events. The Huai River Basin is an area strongly influenced by the East Asian Monsoon system that has experienced a significant increase in rainstorm events together with upward trends of precipitation and duration. It has characteristically large precipitation and temperature variability, which lead to a higher frequency of isolated rainstorm events as well as severe and persistent floods [67]. Because of the ascent of water vapor in the 

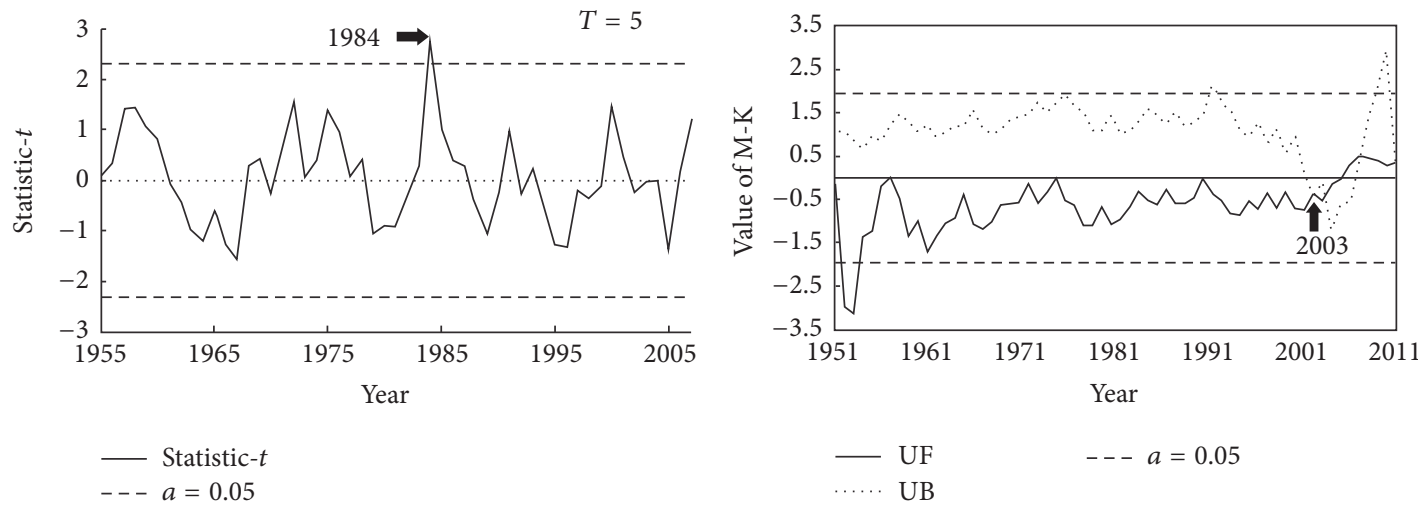

(b) M-K abrupt change test of precipitation
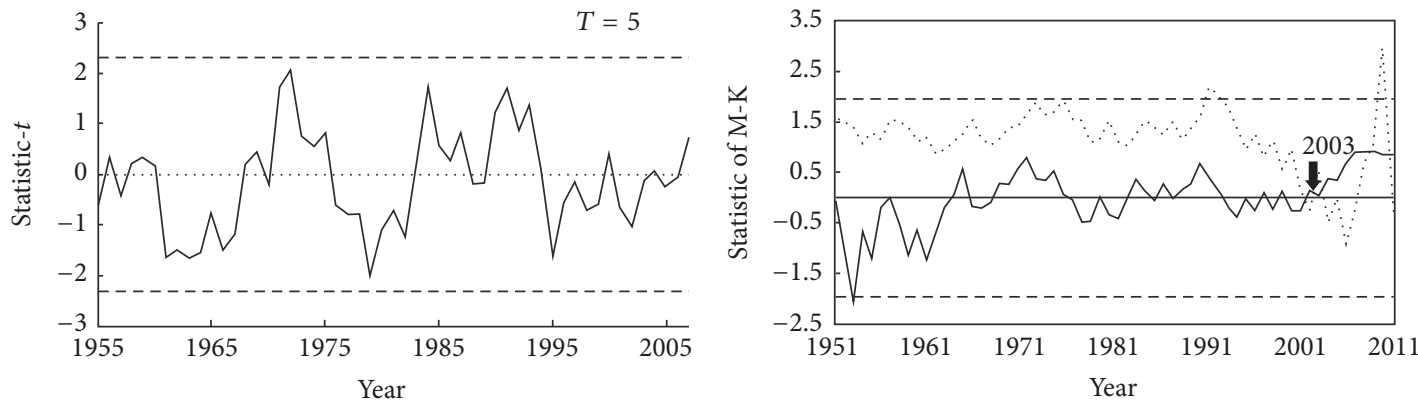

- Statistic- $t$

$---a=0.05$

(c) Moving $t$-test of duration

- UF

$---a=0.05$

(d) M-K abrupt change test of duration
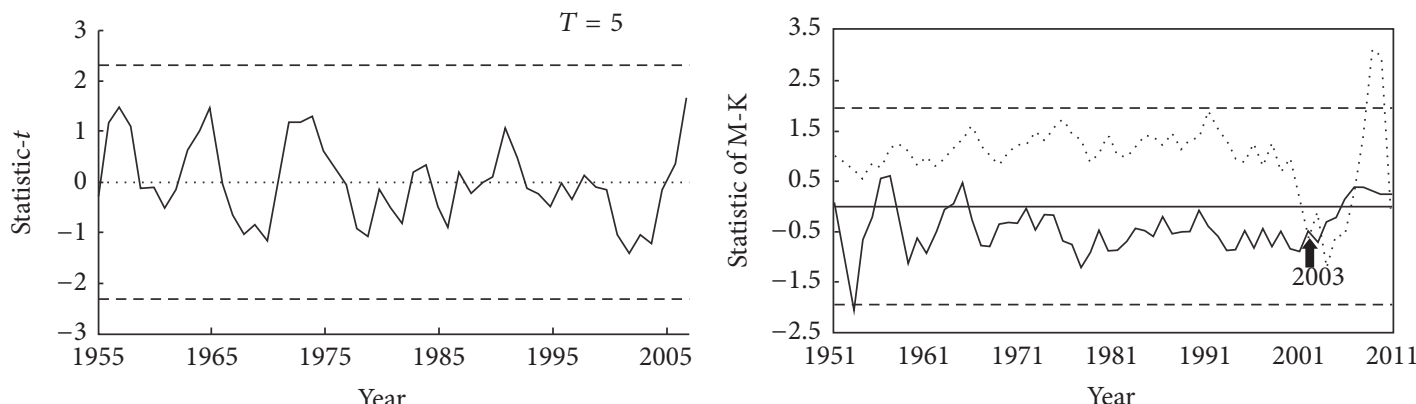

- Statistic- $t$

$---a=0.05$

(e) Moving $t$-test of frequency

- UF

UB

(f) M-K abrupt change test of frequency
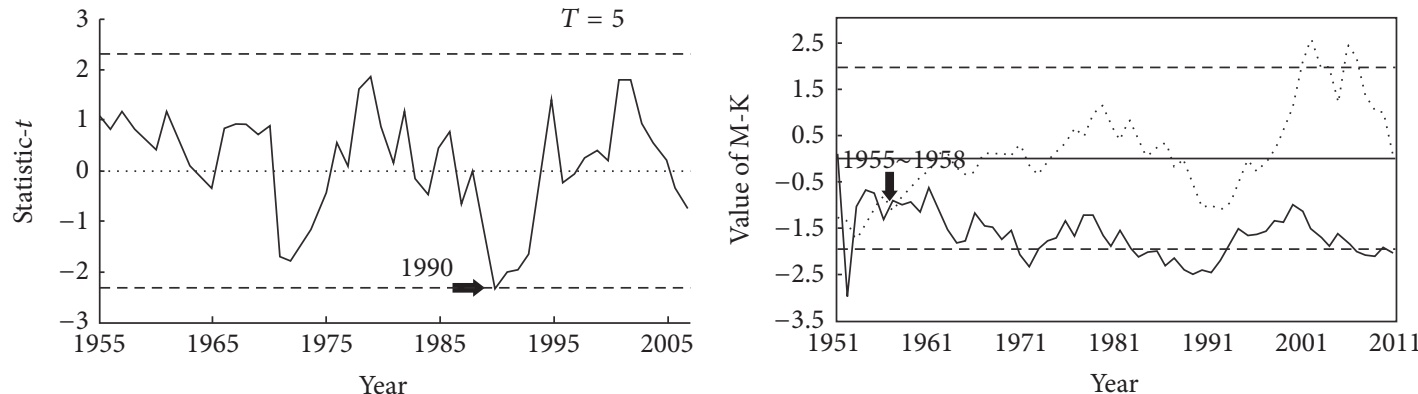

- Statistic- $t$

$---a=0.05$

(g) Moving $t$-test of intensity

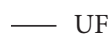

$---a=0.05$

.. UB

(h) M-K abrupt change test of intensity

FIGURE 11: Mutations from Mann-Kendall test and moving $t$-test. 


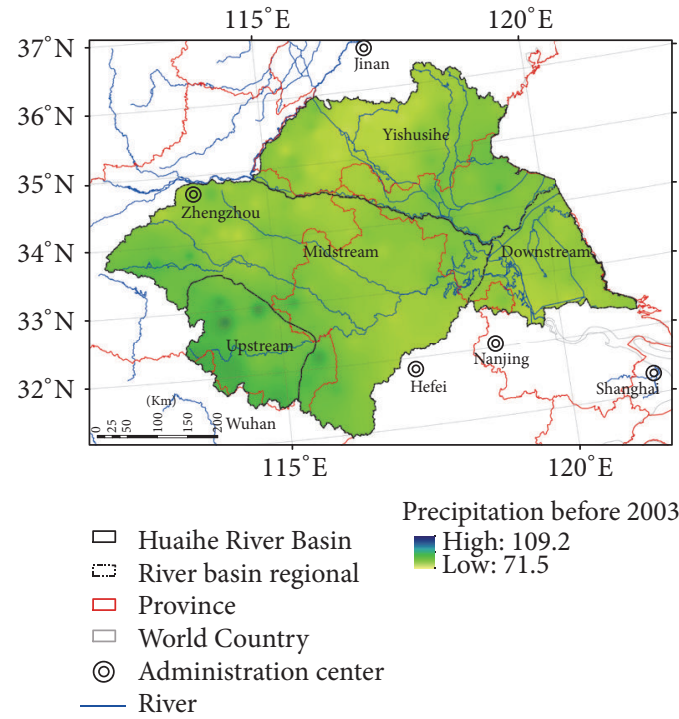

(a)

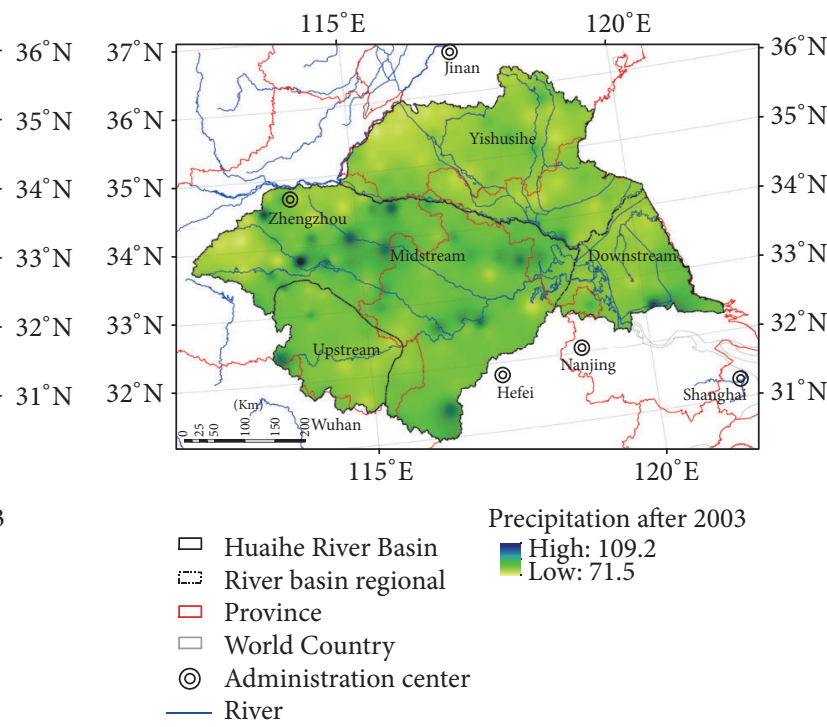

(b)

FIGURE 12: Spatial distribution of isolated rainstorm event precipitation, before and after mutation time.

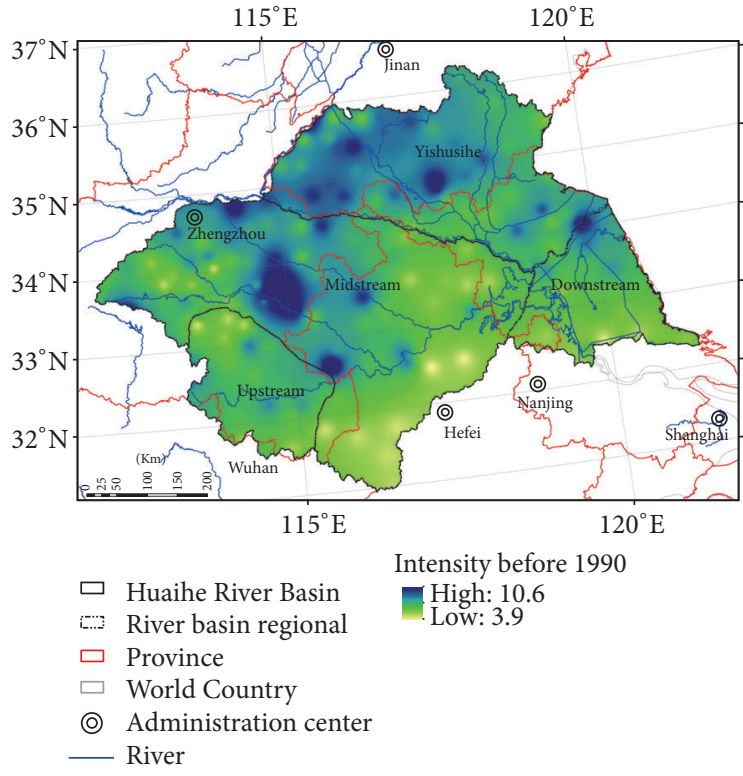

(a)

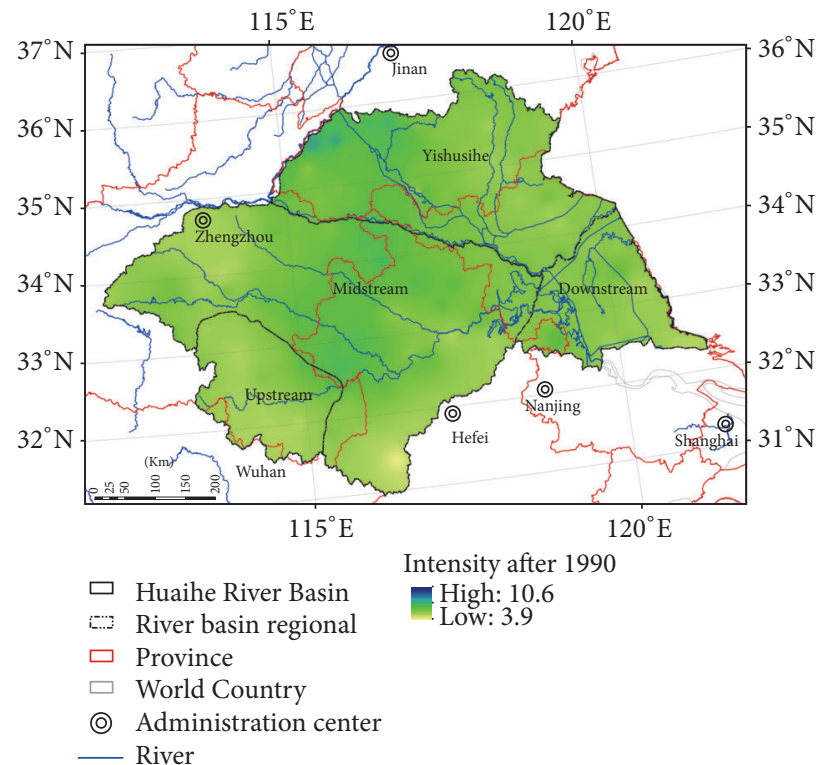

(b)

FIGURE 13: Spatial distribution of isolated rainstorm event intensity, before and after mutation time.

atmosphere, the increase of temperature is deemed to be correlated with the recent increase in extreme precipitation events [68].

\section{Conclusions}

Since the 1950s, the magnitude and frequency of extreme precipitation events in the Huai River Basin have been on the increase. The present study used hourly resolution data to define isolated rainstorm events and analyze the variation of onset time and time to attainment of peak intensity, as well as the variation of precipitation, duration, intensity, and frequency of such events. We present the spatiotemporal variation of these events in the basin; however, the longterm climatological average period may have some effects on extreme climate, and so it may be limited in its use to measure climate change in other shorter periods analyzed. The lack of physically based reasoning for the statistically based results and conclusions given is another limitation of our study. Given the well-known uncertainties of climate change projections, there is also a danger of extrapolating the statistically based results of this paper in the future, 


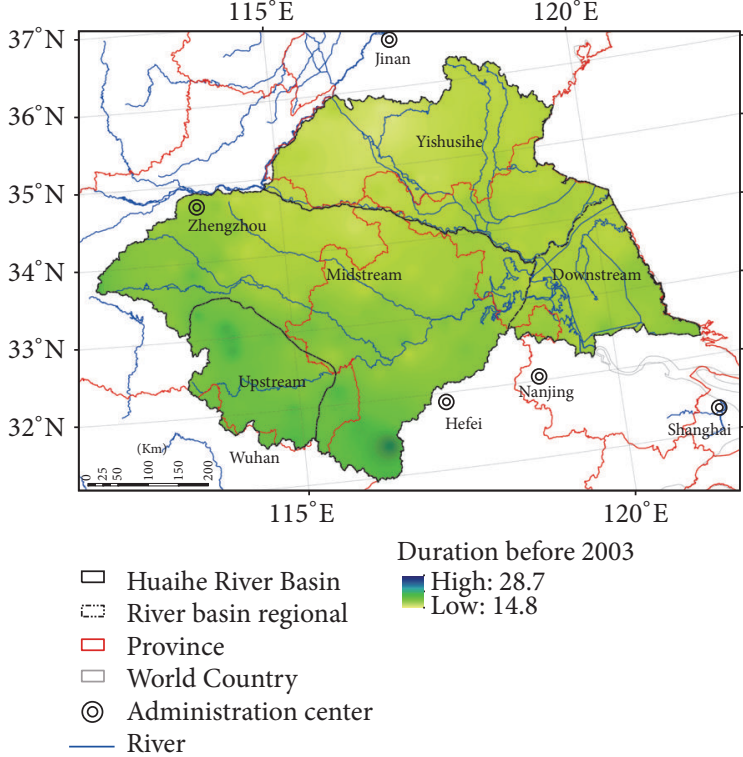

(a)

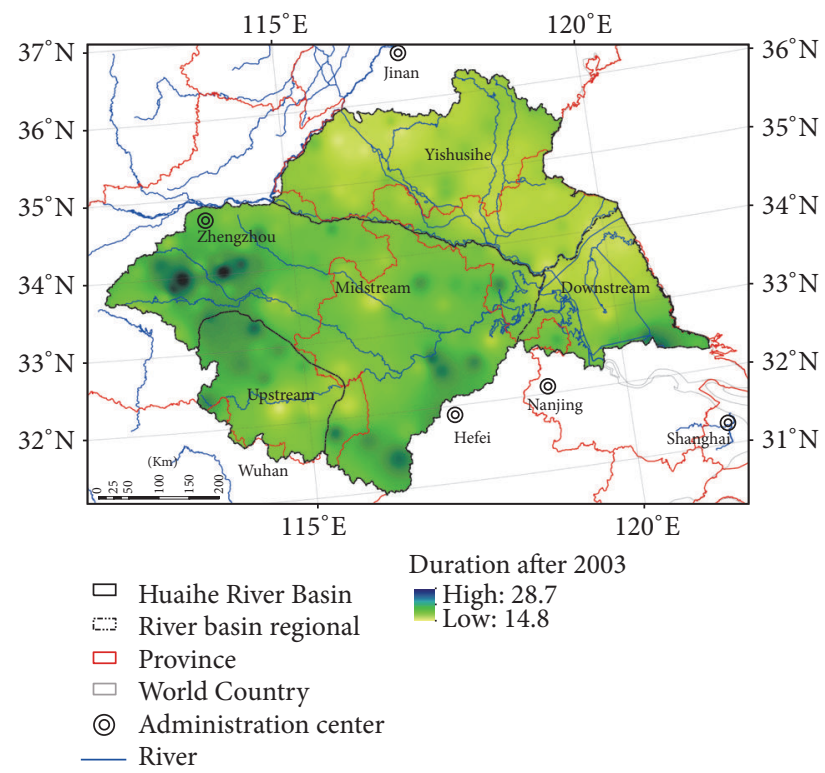

(b)

FIGURE 14: Spatial distribution of isolated rainstorm event duration, before and after mutation time.

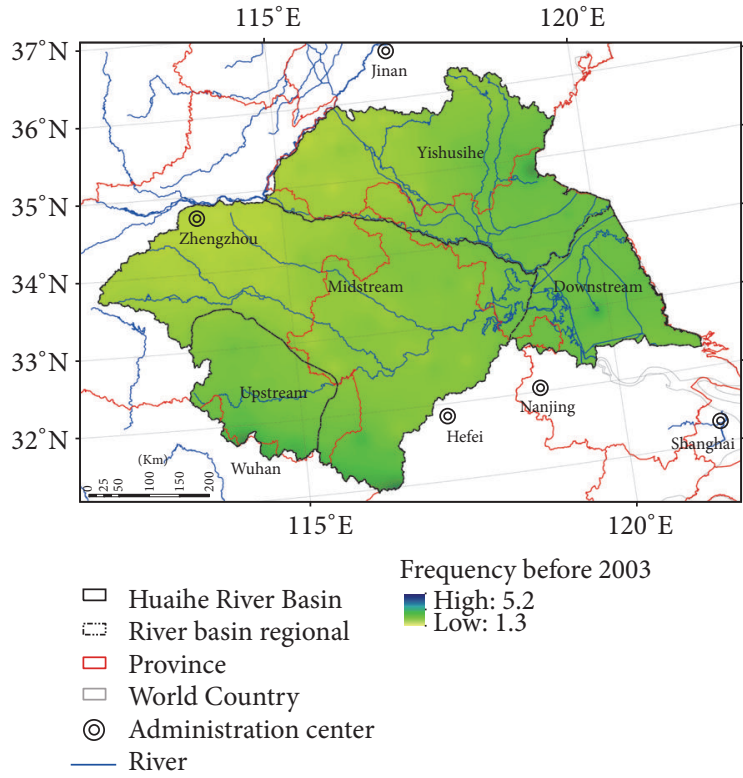

(a)

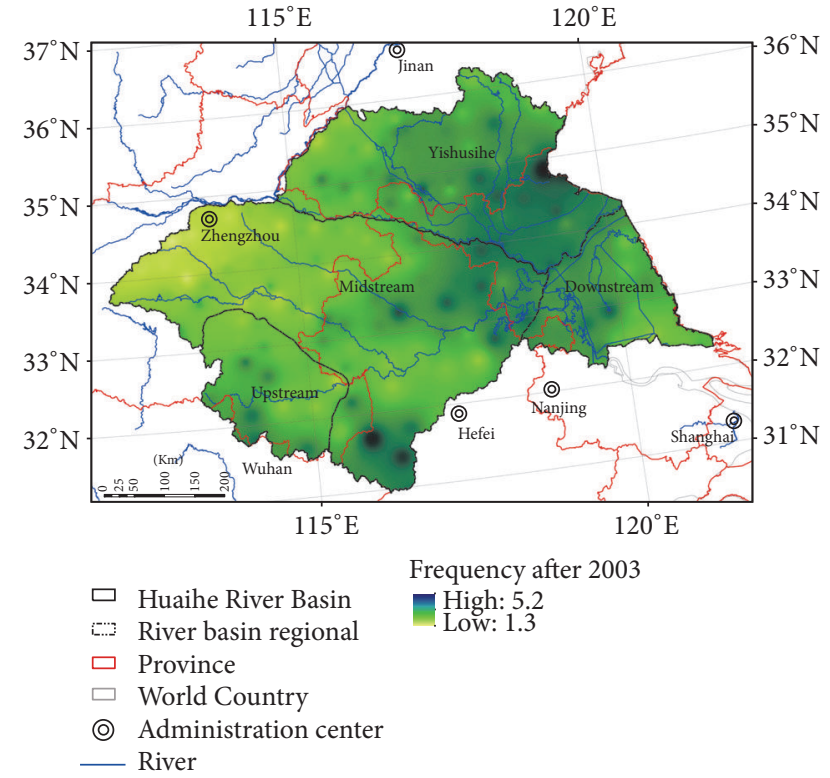

(b)

FIGURE 15: Spatial distribution of isolated rainstorm event frequency, before and after mutation time.

for example, as they relate to water resource management and planning and flood/drought disasters. Future, physically based work is needed to confirm our results.

Based on the latest water census data and a map of large reservoirs in China (Figure 16), we see that the distribution of the 44 large reservoirs in the basin is incompatible with that of the isolated rainstorm events. Most of the latter are in the southwestern area upstream of mountains and in the midstream area, as well as in the central and northern parts of the Yishusi Basin. In the central midstream and entire downstream area, there are almost no large reservoirs. However, over the last 20 years with strengthening impacts of climate change, areas with isolated rainstorm events have covered nearly the entire basin, and the uneven distribution of large reservoirs will seriously affect flood control abilities. Between 1950 and 1979, China completed the construction of numerous water conservancy projects under the "Great Leap Forward." The country now has 87,000 reservoirs, 59\% of which were built in the Huai Basin during the 1950s and 1960s. These reservoirs have now reached the limits of 


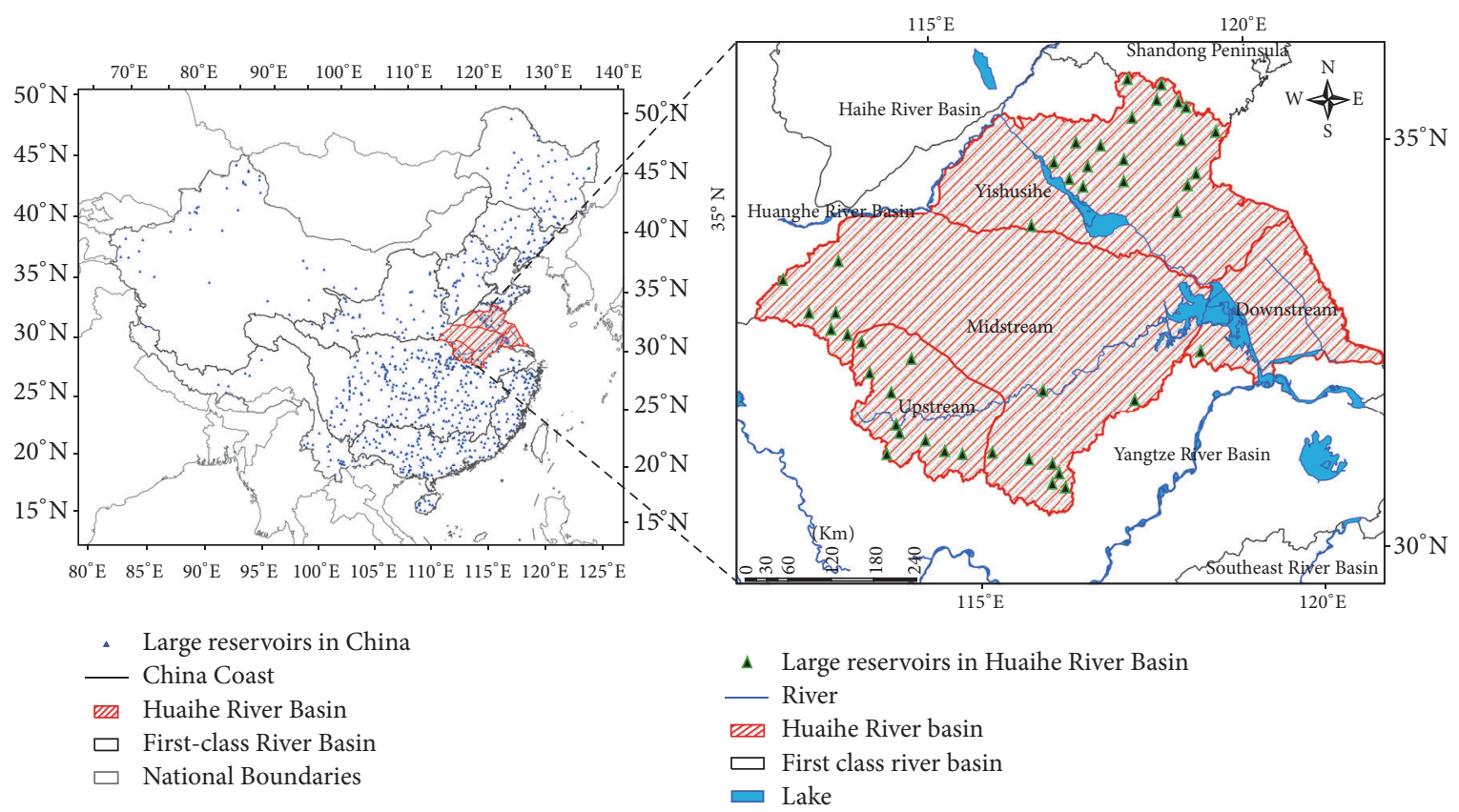

FIGURE 16: Map of large reservoir distribution in Huai River Basin.

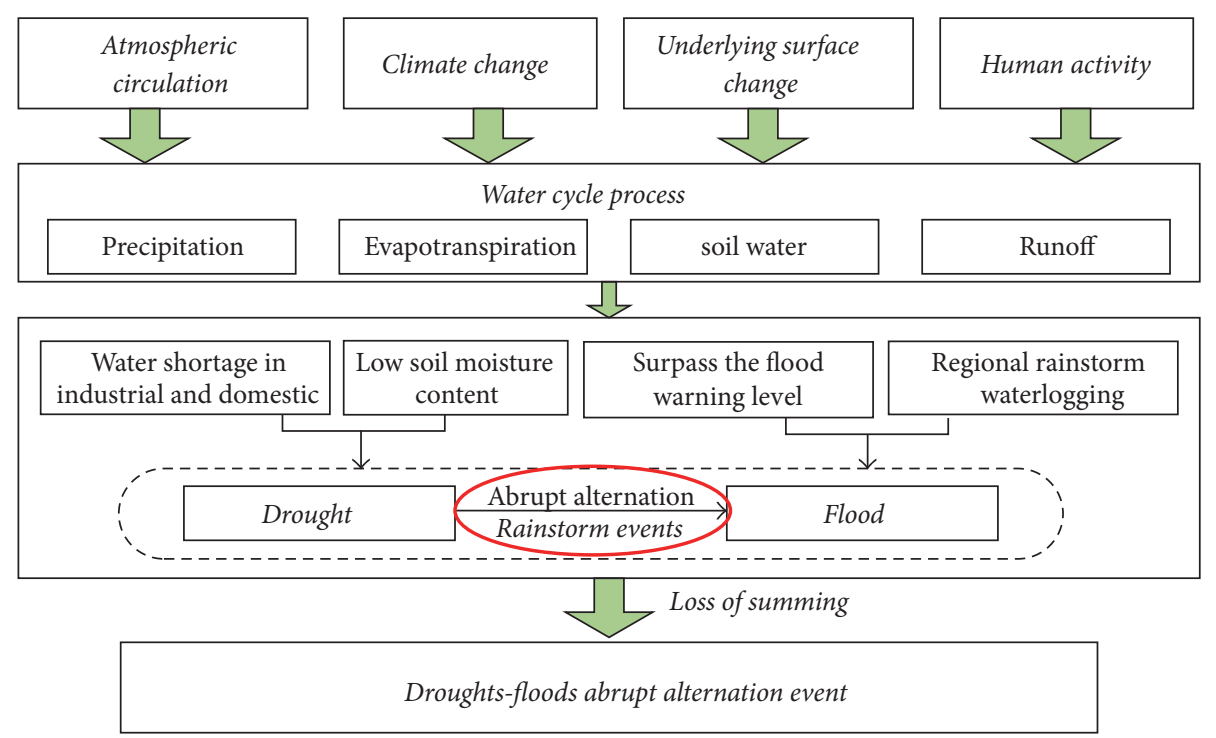

FIGURE 17: Formation mechanisms of drought-flood abrupt alternation.

their design service life of $\sim 50$ years. Because the frequency of rainstorms has significantly increased, the percentage of reservoir fill has obviously increased in the basin, so the threat of rainstorm disaster is much greater than before. Therefore, we suggest strengthening the capabilities of planning and management in water conservancy projects and making the layouts and distributions of those projects more reasonable.

By combining the MK abrupt change and the moving $t$ test methods, we comprehensively determined the mutation points of different indicators. All indices of rainstorm events were shown to mutate during the 1990s-2000s. The indicator of rainstorm intensity showed a significant decreasing trend in 1990. Mutations of other rainstorm indices occurred in 2003.

More frequent and extreme rainstorm events greatly increase the risk of abrupt alternation between drought and flood disaster, which are already typical in the Huai River Basin. The direct mechanisms of anomalous drought and flood disaster were abnormal precipitation (Figure 17), isolated rainstorm events as mutation points, and frequent anomalous droughts and floods greatly impacting the socioeconomy, people's livelihoods and the ecological environment. In recent years, urban rainstorms in the basin have been severe; "a flood every few years" in the past has now 
developed into "a few floods per year." Therefore, we argue for a thorough understanding of the influence of isolated rainstorm events on anomalous drought and flood events and for building sponge basins. This can be achieved by improvements to nonengineering measures, including enhancing the flood-resistant capabilities of vegetation and reasonably adjusting the population and socioeconomic configuration of the entire basin in addition to optimizing engineering measures. This is critical and will have great practical significance to the economics of the basin population in the future.

\section{Competing Interests}

The authors declare that there is no conflict of interests regarding the publication of this paper.

\section{Acknowledgments}

This research is supported by the National Key Research and Development Project (no. 2016YFA0601503) and Research Fund of the State Key Laboratory of Simulation and Regulation of Water Cycle in the River Basin (no. 2016CG02).

\section{References}

[1] J. H. Kotir, "Climate change and variability in Sub-Saharan Africa: a review of current and future trends and impacts on agriculture and food security," Environment, Development and Sustainability, vol. 13, no. 3, pp. 587-605, 2011.

[2] S. D. Solomon, D. Qin, M. Manning et al., Contribution of Working Group I to the Fourth Assessment Report of the Intergovernmental Panel on Climate Change, Cambridge University Press, 2014

[3] S.-K. Min, X. Zhang, F. W. Zwiers, and G. C. Hegerl, "Human contribution to more-intense precipitation extremes," Nature, vol. 470, no. 7334, pp. 378-381, 2011.

[4] S. Feng, Q. Hu, W. Huang, C.-H. Ho, R. Li, and Z. Tang, "Projected climate regime shift under future global warming from multi-model, multi-scenario CMIP5 simulations," Global and Planetary Change, vol. 112, pp. 41-52, 2014.

[5] S. I. Seneviratne, "Changes in climate extremes and their impacts on the natural physical environment," in Managing the Risks of Extreme Events and Disasters to Advance Climate Change Adaptation, chapter 3, Cambridge University Press, 2012.

[6] T. F. Stocker, D. Qin, G. K. Plattner et al., "Climate change 2013: the physical science basis," in Contribution of Working Group I to the Fifth Assessment Report of IPCC the Intergovernmental Panel on Climate Change, pp. 159-254, 2007.

[7] M. Beniston, D. B. Stephenson, O. B. Christensen et al., "Future extreme events in European climate: an exploration of regional climate model projections," Climatic Change, vol. 81, no. 1, pp. 71-95, 2007.

[8] T. Gao and L. Xie, "Multivariate regression analysis and statistical modeling for summer extreme precipitation over the Yangtze River basin, China," Advances in Meteorology, vol. 2014, Article ID 269059, 8 pages, 2014.

[9] H. Du, J. Xia, and S. Zeng, "Regional frequency analysis of extreme precipitation and its spatio-temporal characteristics in the Huai River Basin, China," Natural Hazards, vol. 70, no. 1, pp. 195-215, 2014.

[10] G. Fu, J. Yu, X. Yu et al., “Temporal variation of extreme rainfall events in China, 1961-2009," Journal of Hydrology, vol. 487, pp. 48-59, 2013

[11] X. H. Liu, Z. J. Ji, W. U. Hong-Bao, and Y. U. Xiu-Jing, "Distributing characteristics and interdecadal difference of daily temperature and precipitation extremes in China for latest 40 years," Journal of Tropical Meteorology, vol. 22, no. 6, pp. 618624, 2006 (Chinese).

[12] Z. Yuan, Z. Yang, D. Yan, and J. Yin, "Historical changes and future projection of extreme precipitation in China," Theoretical and Applied Climatology, vol. 127, no. 1, pp. 393-407, 2017.

[13] L. Borgatti and M. Soldati, "Landslides and climatic change," Journal of Aerosol Science, vol. 26, supplement 1, pp. 1-2, 2010.

[14] H. Chen and J. Sun, "Changes in climate extreme events in China associated with warming," International Journal of Climatology, vol. 35, no. 10, pp. 2735-2751, 2015.

[15] Y. Xu, J. Yang, and Y. Chen, "NDVI-based vegetation responses to climate change in an arid area of China," Theoretical and Applied Climatology, vol. 126, no. 1, pp. 213-222, 2016.

[16] C. H. Wu, G. R. Huang, and H. J. Yu, "Prediction of extreme floods based on CMIP5 climate models: a case study in the Beijiang River basin, South China," Hydrology and Earth System Sciences, vol. 19, no. 3, pp. 1385-1399, 2015.

[17] R.-L. Ll and S. Geng, "Impacts of climate change on agriculture and adaptive strategies in China," Journal of Integrative Agriculture, vol. 12, no. 8, pp. 1402-1408, 2013.

[18] C. Xu, X.-G. Yang, Y. Li, and W.-F. Wang, "Changes of China agricultural climate resources under the background of climate change. III. Spatiotemporal change characteristics of agricultural climate resources in Northwest Arid Area," Chinese Journal of Applied Ecology, vol. 22, no. 3, pp. 763-772, 2011 (Chinese).

[19] Z. Yuan, D. Yan, Z. Yang, J. Yin, P. Breach, and D. Wang, "Impacts of climate change on winter wheat water requirement in Haihe River Basin," Mitigation and Adaptation Strategies for Global Change, vol. 21, no. 5, pp. 677-697, 2016.

[20] S.-W. Dai, X.-G. Yang, M. Zhao, Y. Li, W.-F. Wang, and Z.-J. Liu, "Changes of China agricultural climate resources under the background of climate change. II. Spatiotemporal change characteristics of agricultural climate resources in Southwest China," Chinese Journal of Applied Ecology, vol. 22, no. 2, pp. 442-452, 2011 (Chinese).

[21] Y. Li, X.-G. Yang, W.-F. Wang, and Z.-J. Liu, "Changes of China agricultural climate resources under the background of climate change I. Spatiotemporal change characteristics of agricultural climate resources in South China," Chinese Journal of Applied Ecology, vol. 21, no. 10, pp. 2605-2614, 2010 (Chinese).

[22] F. Tao, M. Yokozawa, Z. Zhang, Y. Hayashi, H. Grassl, and C. $\mathrm{Fu}$, "Variability in climatology and agricultural production in China in association with the East Asian summer monsoon and El Niño Southern Oscillation," Climate Research, vol. 28, no. 1, pp. 23-30, 2004.

[23] Y. Ding, Z. Wang, and Y. Sun, "Inter-decadal variation of the summer precipitation in East China and its association with decreasing Asian summer monsoon. Part I: observed evidences," International Journal of Climatology, vol. 28, no. 9, pp. 1139-1161, 2008.

[24] J. C. Neal, P. D. Bates, T. J. Fewtrell, N. M. Hunter, M. D. Wilson, and M. S. Horritt, "Distributed whole city water level measurements from the Carlisle 2005 urban flood event 
and comparison with hydraulic model simulations," Journal of Hydrology, vol. 368, no. 1-4, pp. 42-55, 2009.

[25] R. I. Dorn, "Impact of consecutive extreme rainstorm events on particle transport: case study in a Sonoran Desert range, western USA," Geomorphology, vol. 250, pp. 53-62, 2015.

[26] T.-J. Zhou and R.-C. Yu, "Atmospheric water vapor transport associated with typical anomalous summer rainfall patterns in China," Journal of Geophysical Research D: Atmospheres, vol. 110, no. 8, pp. 1-10, 2005.

[27] S. B. Trier, J. H. Marsham, C. A. Davis, and D. A. Ahijevych, "Numerical simulations of the postsunrise reorganization of a nocturnal mesoscale convective system during 13 june IHOP_2002," Journal of the Atmospheric Sciences, vol. 68, no. 12, pp. 2988-3011, 2011.

[28] X. Wu, D. Yu, Z. Chen, and R. L. Wilby, "An evaluation of the impacts of land surface modification, storm sewer development, and rainfall variation on waterlogging risk in Shanghai," Natural Hazards, vol. 63, no. 2, pp. 305-323, 2012.

[29] Y. Liu, Z. Chen, J. Wang, B. Hu, M. Ye, and S. Xu, "Large-scale natural disaster risk scenario analysis: a case study of Wenzhou City, China," Natural Hazards, vol. 60, no. 3, pp. 1287-1298, 2012.

[30] R. Quan, "Risk assessment of flood disaster in Shanghai based on spatial-temporal characteristics analysis from 251 to 2000," Environmental Earth Sciences, vol. 72, no. 11, pp. 4627-4638, 2014.

[31] X. Zhang, M. Hu, G. Chen, and Y. Xu, "Urban rainwater utilization and its role in mitigating urban waterlogging problemsa case study in Nanjing, China," Water Resources Management, vol. 26, no. 13, pp. 3757-3766, 2012.

[32] A. H. Elliott and S. A. Trowsdale, "A review of models for low impact urban stormwater drainage," Environmental Modelling and Software, vol. 22, no. 3, pp. 394-405, 2007.

[33] J. Xia, D. She, Y. Zhang, and H. Du, "Spatio-temporal trend and statistical distribution of extreme precipitation events in Huaihe River Basin during 1960-2009," Journal of Geographical Sciences, vol. 22, no. 2, pp. 195-208, 2012.

[34] Y. He, X. Mu, P. Gao et al., "Spatial variability and periodicity of precipitation in the middle reaches of the yellow river, China," Advances in Meteorology, vol. 2016, Article ID 9451614, 9 pages, 2016.

[35] Q. Li, Y. Chen, Y. Shen, X. Li, and J. Xu, "Spatial and temporal trends of climate change in Xinjiang, China," Journal of Geographical Sciences, vol. 21, no. 6, pp. 1007-1018, 2011.

[36] Z. Xing, D. Yan, C. Zhang, G. Wang, and D. Zhang, "Spatial characterization and bivariate frequency analysis of precipitation and runoff in the Upper Huai River Basin, China," Water Resources Management, vol. 29, no. 9, pp. 3291-3304, 2015.

[37] Y. He, J. Ye, and X. Yang, "Analysis of the spatio-temporal patterns of dry and wet conditions in the Huai River Basin using the standardized precipitation index," Atmospheric Research, vol. 166, pp. 120-128, 2015.

[38] Y. Zhang, Q. Shao, J. Xia, S. Bunn, and Q. Zuo, "Changes of flow regimes and precipitation in Huai River Basin in the last half century," Hydrological Processes, vol. 25, no. 2, pp. 246-257, 2011.

[39] J. Chen and B. J. Adams, "Analysis of storage facilities for urban stormwater quantity control," Advances in Water Resources, vol. 28, no. 4, pp. 377-392, 2005.

[40] T. Masumoto, H. Sato, K. Iwasaki, and K. Shibuya, "Selected variograms and optimal network design of rainfall observation facilities," in Stochastic and Statistical Methods in Hydrology and Environmental Engineering, Water Science and Technology Library, pp. 193-205, 1994.
[41] L. L. Dyson, "Heavy daily-rainfall characteristics over the gauteng province," Water SA, vol. 35, no. 5, pp. 627-638, 2009.

[42] G. Y. Lu and D. W. Wong, "An adaptive inverse-distance weighting spatial interpolation technique," Computers and Geosciences, vol. 34, no. 9, pp. 1044-1055, 2008.

[43] D. F. Watson, "A refinement of inverse distance weighted interpolation," Geo-Processing, vol. 2, no. 2, pp. 315-327, 1985.

[44] I. A. Nalder and R. W. Wein, "Spatial interpolation of climatic normals: test of a new method in the Canadian boreal forest," Agricultural and Forest Meteorology, vol. 92, no. 4, pp. 211-225, 1998.

[45] M. Garcia, C. D. Peters-Lidard, and D. C. Goodrich, "Spatial interpolation of precipitation in a dense gauge network for monsoon storm events in the southwestern United States," Water Resources Research, vol. 44, no. 5, pp. 782-781, 2008.

[46] C. Onyutha, H. Tabari, M. T. Taye, G. N. Nyandwaro, and P. Willems, "Analyses of rainfall trends in the Nile River Basin," Journal of Hydro-Environment Research, vol. 13, pp. 36-51, 2016.

[47] P. Yang, J. Xia, Y. Zhang, and S. Hong, “Temporal and spatial variations of precipitation in Northwest China during 19602013," Atmospheric Research, vol. 183, pp. 283-295, 2017.

[48] S. H. Bari, M. T. U. Rahman, M. A. Hoque, and M. M. Hussain, "Analysis of seasonal and annual rainfall trends in the northern region of Bangladesh," Atmospheric Research, vol. 176-177, pp. 148-158, 2016.

[49] S. Yue, P. Pilon, and G. Cavadias, "Power of the Mann-Kendall and Spearman's rho tests for detecting monotonic trends in hydrological series," Journal of Hydrology, vol. 259, no. 1-4, pp. 254-271, 2002.

[50] S. Yue and C. Wang, "The Mann-Kendall test modified by effective sample size to detect trend in serially correlated hydrological series," Water Resources Management, vol. 18, no. 3, pp. 201-218, 2004.

[51] Q. Zhang, M. Gemmer, and J. Chen, "Climate changes and flood/drought risk in the Yangtze Delta, China, during the past millennium," Quaternary International, vol. 176-177, no. C, pp. 62-69, 2008.

[52] Z. Yang, Z. Yuan, J. Ma, and H. Fang, "Evloution characteristics of drought and flood in Huaihe River basin in recent 50 years," Journal of Natural Disasters, vol. 22, no. 4, pp. 32-40, 2013 (Chinese).

[53] W. Tao, T. Hui, and Y. Qiang, "Characteristics of inter-annual and seasonal changes in temperature and precipitation over the Nantong Region during the period 1960-2007," Resources Science, vol. 33, no. 11, pp. 2080-2089, 2011 (Chinese).

[54] P. Yang, N. Wang, C. Wang, and S. Cao, "Analysis on the temperature change in Qinghai lake region: 1960-2007," Journal of Qinghai University (Natural Science), vol. 29, no. 2, pp. 49-53, 2011 (Chinese).

[55] L. Li, W. Li, Q. Tang, P. Zhang, and Y. Liu, "Warm season heavy rainfall events over the Huaihe River Valley and their linkage with wintertime thermal condition of the tropical oceans," Climate Dynamics, vol. 46, no. 1, pp. 71-82, 2016.

[56] H. Yang and C. Li, "The relation between atmospheric intraseasonal oscillation and summer severe flood and drought in the Changjiang-Huaihe River Basin," Advances in Atmospheric Sciences, vol. 20, no. 4, pp. 540-553, 2003.

[57] D. R. Easterling, G. A. Meehl, C. Parmesan, S. A. Changnon, T. R. Karl, and L. O. Mearns, "Climate extremes: observations, modeling, and impacts," Science, vol. 289, no. 5487, pp. 20682074, 2000. 
[58] M. J. Manton, P. M. Della-Marta, M. R. Haylock et al., “Trends in extreme daily rainfall and temperature in southeast Asia and the south Pacific: 1961-1998," International Journal of Climatology, vol. 21, no. 3, pp. 269-284, 2001.

[59] P. Zhai, X. Zhang, H. Wan, and X. Pan, "Trends in total precipitation and frequency of daily precipitation extremes over China," Journal of Climate, vol. 18, no. 7, pp. 1096-1108, 2005.

[60] L. V. Alexander, X. Zhang, T. C. Peterson et al., "Global observed changes in daily climate extremes of temperature and precipitation," Journal of Geophysical Research Atmospheres, vol. 111, no. 5, pp. 1042-1063, 2012.

[61] K.-M. Lau, H.-T. Wu, and S. Bony, "The role of large-scale atmospheric circulation in the relationship between tropical convection and sea surface temperature," Journal of Climate, vol. 10, no. 3, pp. 381-392, 1997.

[62] J. Corte-Real, B. Qian, and H. Xu, "Regional climate change in Portugal: precipitation variability associated with large-scale atmospheric circulation," International Journal of Climatology, vol. 18, no. 6, pp. 619-635, 1998.

[63] J. Jaagus, "Climatic changes in Estonia during the second half of the 20th century in relationship with changes in large-scale atmospheric circulation," Theoretical and Applied Climatology, vol. 83, no. 1-4, pp. 77-88, 2006.

[64] J. Jaagus, P. Post, and O. Tomingas, "Changes in storminess on the western coast of Estonia in relation to large-scale atmospheric circulation," Climate Research, vol. 36, no. 1, pp. 2940, 2008.

[65] Q. You, S. Kang, E. Aguilar et al., "Changes in daily climate extremes in China and their connection to the large scale atmospheric circulation during 1961-2003," Climate Dynamics, vol. 36, no. 11-12, pp. 2399-2417, 2011.

[66] S. Piao, P. Ciais, Y. Huang et al., "The impacts of climate change on water resources and agriculture in China," Nature, vol. 467, no. 7311, pp. 43-51, 2010.

[67] J. Zheng, W.-C. Wang, Q. Ge, Z. Man, and P. Zhang, "Precipitation variability and extreme events in eastern China during the past 1500 years," Terrestrial, Atmospheric and Oceanic Sciences, vol. 17, no. 3, pp. 579-592, 2006.

[68] Q. Zhang, V. P. Singh, J. Li, F. Jiang, and Y. Bai, "Spatio-temporal variations of precipitation extremes in Xinjiang, China," Journal of Hydrology, vol. 434-435, no. 2, pp. 7-18, 2012. 

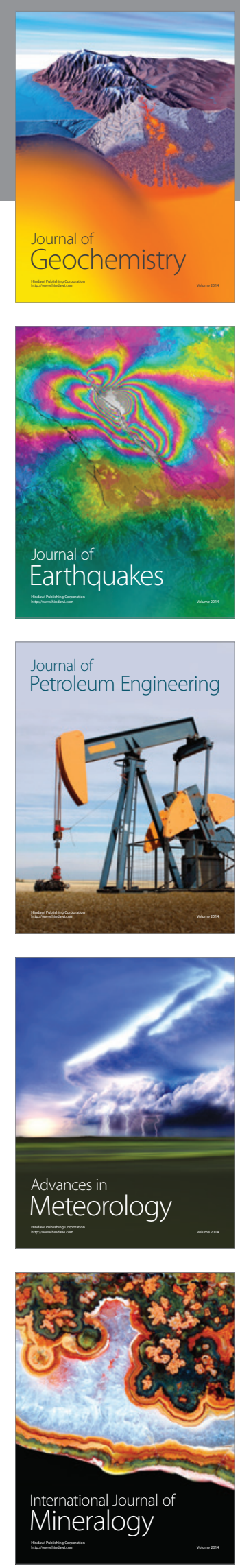
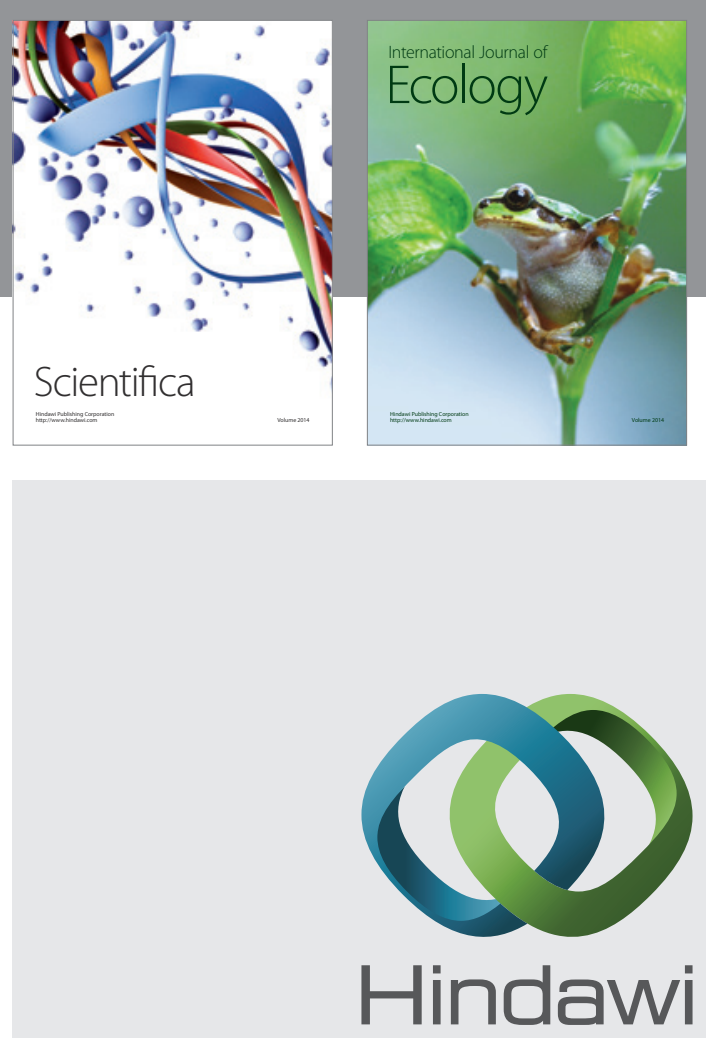

Submit your manuscripts at

https://www.hindawi.com
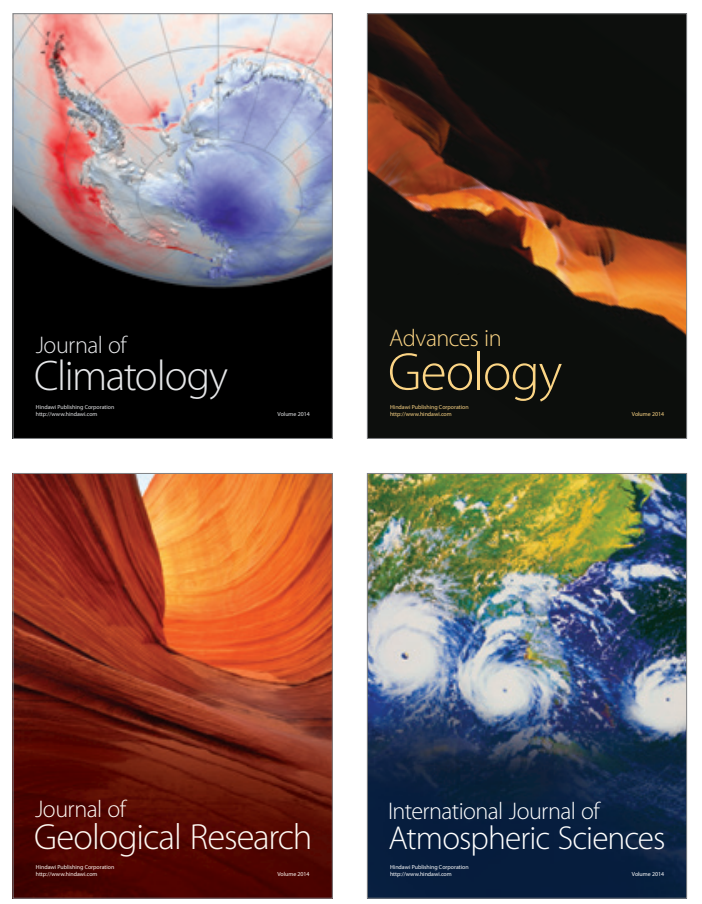

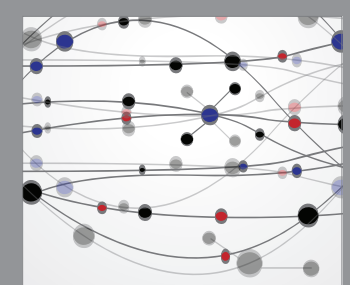

The Scientific

\section{World Journal}
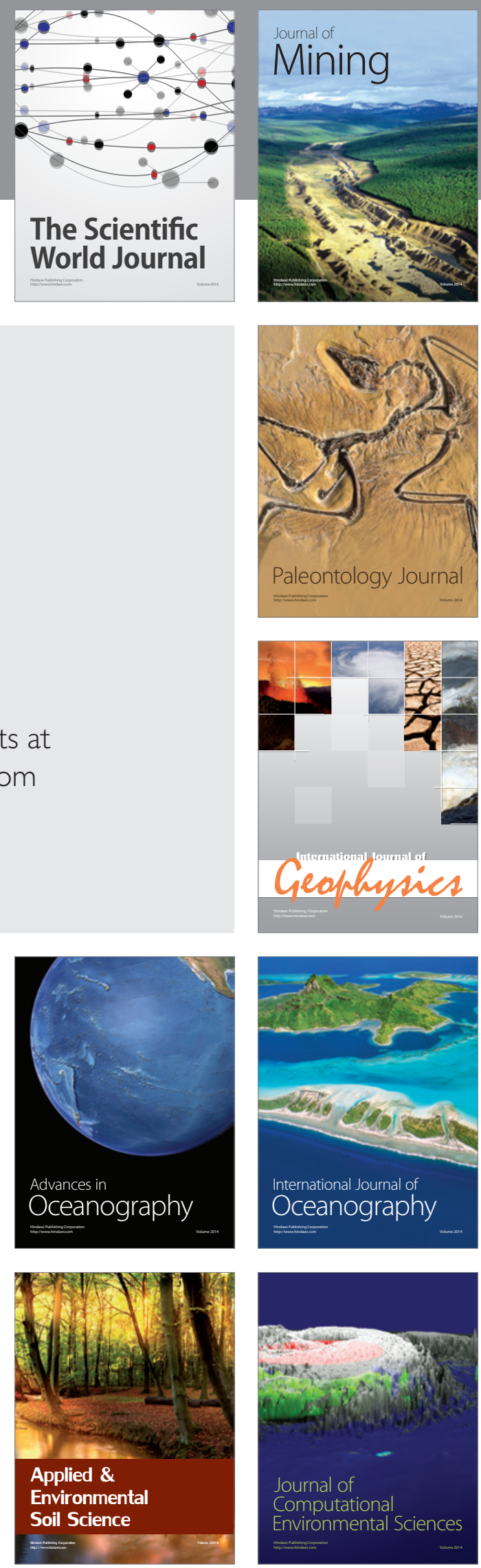